\title{
Healing and Growth of Half-Eye "Compound Eyes" in Xenopus: Application of an Interspecific Cell Marker
}

\author{
Stephen O'Gorman, John Kilty, and R. Kevin Hunt \\ The Salk Institute for Biological Studies and Clayton Foundation for Research-California Division, La Jolla, California 92037
}

Surgically constructed compound eyes have been widely used to examine the development of retinotectal projections in amphibians. Such studies have been limited, however, by the lack of an adequate cellular marker with which to assess the contributions of grafted and host tissues to the later larval and adult retina. We have followed the growth of graftand host-derived ocular tissues in interspecific compound eyes prepared by orthotopic and heterotopic exchanges of half-eye fragments between pigmented Xenopus borealis and albino Xenopus laevis embryos. This genotypic combination allowed the growth of graft-derived choroid and pigment epithelium to be studied in the living animal, and permitted cell-by-cell resolution of graft- and host-derived neurons in quinacrine-stained paraffin sections.

At mid- and late-larval stages graft-derived neurons occupied large and usually coherent territories of retina in all classes of orthotopic and heterotopic compound eyes. In successfully healed cases, sample means of the percentage of the total retina occupied by graft-derived neurons ranged from 43 to $51 \%$. Graft-derived territories originated near the optic nerve head and extended into the germinal neuroepithelium at the retinal periphery. As compared to orthotopic compound eyes, graft-derived territories in all classes of heterotopic compound eyes were slightly smaller and significantly more variable. Despite this variability, the correlation between graft-derived pigment epithelial and retinal territories was quite good in heterotopic compound eyes.

While graft-host borders were generally sharp, there was also evidence of local cell mixing over distances of several cell diameters in the inner nuclear and ganglion cell layers. Single displaced cells, isolated from other members of their genetic cohort by 5 or more cell diameters, were also present in the inner nuclear and ganglion cell layers.

The formation of retinotectal projections is a complex process involving a variety of cellular interactions and mechanisms. Yet a general consensus exists that positional information (Wolpert, 1971 ) is expressed by ganglion cells as a set of locus-specific chemical markers essential to the formation of orderly retino-

Received Mar. 24, 1986; revised Apr. 15, 1987; accepted Apr. 23, 1987.

We wish to thank Dr. Antonie Blacker for generously providing $X$. borealis mating pairs used for this report, Timothy Hetherington and Kris Trulock for photographic assistance, Robert Durkin and William Lum for animal care, and Pat Thomas for preparing the manuscript. This work was supported by NSF Grant PCM-83-1 1082 to R.K.H., NIH Fellowship EYO 5853 to S.O'G., and funds from the Keck Foundation.

Correspondence should be addressed to Dr. Stephen O'Gorman, Gene Expression Laboratory, The Salk Institute, P.O. Box 85800, San Diego, CA 92138.

Copyright (C) 1987 Society for Neuroscience $0270-6474 / 87 / 113764-19 \$ 02.00 / 0$ tectal projections (Sperry, 1965; Meyer, 1982; Constantine-Paton et al., 1983; Harris, 1984; Easter, 1985; Cowan and Hunt, 1985). In the intact amphibian eye, the pattern of positional specification quickly becomes refractory to extraocular polarizing cues (Stone, 1960; Szekely, 1966; Jacobson, 1968a; Hunt and Jacobson, 1972, 1973a; Gaze et al., 1979). Thereafter, surgical fusion of noncomplementary fragments of eye anlagen to form chimeric or "compound" eyes represents a powerful assay for positional specification (see Harrison, 1933, 1945), for it creates intraocular mismatches in the polarities of positional specification gradients (Gaze et al., 1963, 1965; Hunt and Jacobson, 1973a, b; Hunt and Frank, 1975; Gaze and Straznicky, 1980). By this means, ganglion cells arising from grafted tissues are challenged to cither ignore their new local context and project to tectal targets appropriate to the original retinal address of their progenitors, or, conversely, to respond to their new context by adopting an altered set of locus specificities.

Studies of compound eyes have generally assumed that grafted tissues are successfully integrated and contribute to further ocular histogenesis in a manner consistant with surgical design. The assumption has not been rigorously tested for those classes of compound eyes whose retinotectal projections suggest remodeling of locus specificities within graft-derived retinal territories (Hunt and Jacobson, 1973b; Hunt and Frank, 1975; Ide et al., 1979; Conway et al., 1980; Gaze and Straznicky, 1980; Willshaw et al., 1983). Preliminary efforts to address this problem, using cell-autonomous genetic markers determined by nucleolar number (Elsdale et al., 1958) or ploidy (Reinschmidt et al., 1979), have shown that grafted ocular fragments generally survive to populate a sector territory in the adult retina that extends from near the optic nerve head (representing the originally grafted tissue and tissue generated soon thereafter) to the retinal periphery (representing tissue generated at successively later stages of retinal growth; Hunt and Ide, 1977; Conway et al., 1980; Hunt et al., 1982). However, both markers proved to be cumbersome to use and their resolution was limited because splitting of nuclei during tissue sectioning generates falsely marked and unmarked nuclear profiles.

A new marker system for Xenopus has been developed that takes advantage of the distinctly different appearance of $X$. borealis and $X$. laevis cell nuclei in tissues stained with acridine dyes such as quinacrine (Thiebaud, 1983). Stained $X$. borealis nuclei contain numerous flecks of intensely fluorescent material, while $X$. laevis nuclei are uniformly fluorescent. This contrast appears to reflect differences in the interspersion of GC and AT base pairs within a highly repetitive genomic DNA species (Brown and Sugimoto, 1974; Pardue, 1974). The conceptual elegance of a marker based on such a difference is obvious, for genomic DNA is faithfully transmitted to all cells of a lineage, regardless 
A.

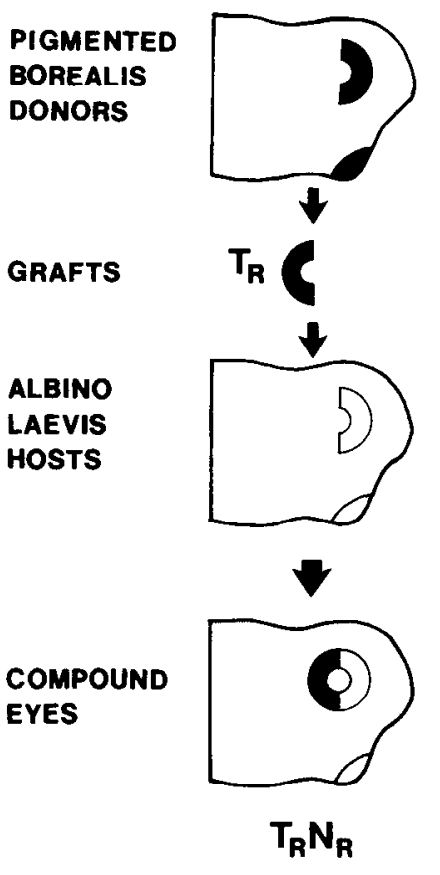

B.

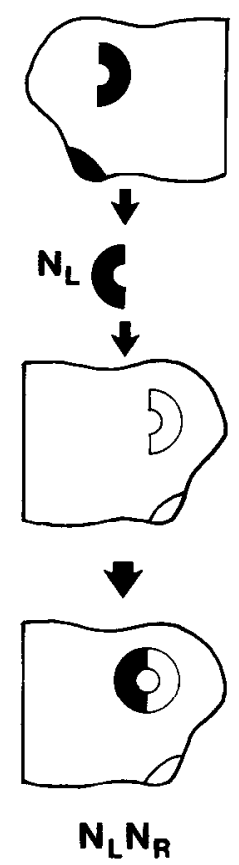

C.

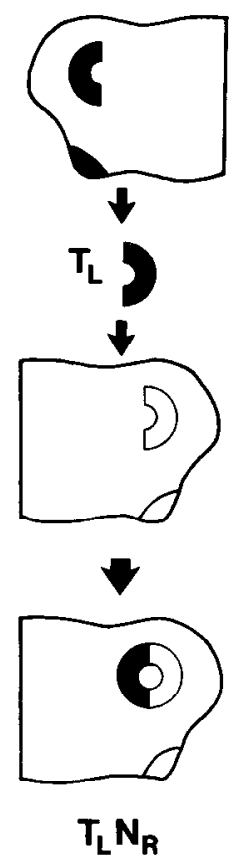

D.
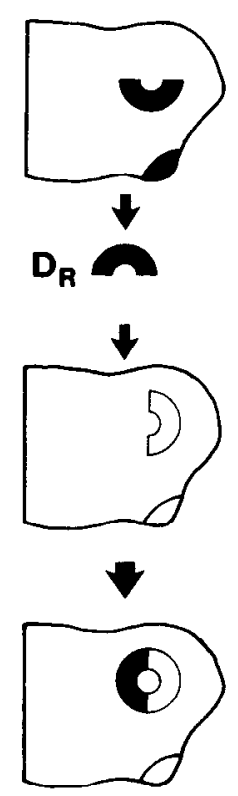

$D_{R} N_{R}$
Figure 1. Operational schematic. The four classes of compound eyes prepared for this report are arrayed in individual vertical columns. $A$, TrNr. $B, \mathrm{NINr} . C$, TITr. $D$, DrNr. of their differentiated fate. This promise has been borne out in practice; the difference in nuclear staining is apparent in all tissues at a variety of developmental stages and has been faithfully expressed in surgical chimeras (Thiebaud, 1983; Winklbauer and Hausen, 1983).

This report describes the distribution of graft- and host-derived retinal territories in compound eyes prepared by grafting half-eye fragments of pigmented $X$. borealis donor embryos into albino $X$. laevis host embryos. We characterize the suitability of the $X$. borealis $-X$. laevis marking system for following the fates of graft-derived tissues in retinal chimeras, quantify the territories populated by graft-derived neurons in the various classes of compound eyes we have prepared, describe deviant cases, and comment on some interesting features of graft-host retinal borders. A preliminary account of these experiments has been presented previously (O'Gorman et al., 1985).

\section{Materials and Methods}

Animals. Normally pigmented donor embryos were obtained from induced (Gurdon, 1967) spawnings of $X$. borealis mating pairs, and albino host embryos from albino $\left(\mathrm{a}^{\mathrm{P}} / \mathrm{a}^{\mathrm{P}}\right.$; Hoperskaya 1975$) X$. laevis mating pairs. Additional (hybrid) pigmented donors were produced by mating $X$. borealis females to albino $X$. laevis males. Mating pairs, larvae, and embryos were maintained in a solution, hereafter referred to as "rearing medium" (RM) equivalent to 5\% Steinberg's and 15\% Holtfreter's solutions. Embryos were staged according to the normal table of Nieuwkoop and Faber (1967). They were collected at early to late blastula stages and split into 2 groups. One group was maintained at room temperature $\left(20 \pm 2^{\circ} \mathrm{C}\right)$ and a second was refrigerated at $12^{\circ} \mathrm{C}$ to slow development and thereby extend the availability of stage 31-36 embryos for up to $5 \mathrm{~d}$ after spawning. Chilled embryos were equilibrated to room temperature over at least a $4 \mathrm{hr}$ period before grafting.

Grafting. Grafting was done at $20-23^{\circ} \mathrm{C}$ in $\mathrm{RM}$ containing tricane methane sulfonate at a dilution of 1:5000 (wt/vol). Donor and host embryos were hetween stages 31 and 36 . To prepare host embryos, a single, sharpened forcep blade was inserted through the ectoderm at the midline ventral margin of the ocular anlagen and then pushed underneath the anlagen for the full length of the vertical meridian before making a single cut through presumptive pigment epithelium, neural retina, lens, and overlying ectoderm. The temporal half-eye fragments were then peeled away from surrounding mesoderm and overlying ectoderm to create wounds bounded laterally by ectodermal flaps. Donor fragments were prepared by analogous maneuvers and inserted into host wounds, retained by the hosts' ectodermal flap. Embryos were left undisturbed in the operating dish for a further 5-10 min and then transferred to RM.

Four classes of compound eyes, designated $\mathrm{TrNr}, \mathrm{NINr}, \mathrm{TlNr}$, and DrNr were prepared as schematized in Figure 1. ( $\mathrm{T}$ and $\mathrm{N}$ designate temporal and nasal half-eye fragments, and $\mathrm{r}$ and 1 indicate whether these fragments were taken from right or left ocular anlagen.) Most orthotopic compound eyes and all heterotopic compound eyes included a $\mathrm{Nr}$ host fragment. A few orthotopic compound eyes were prepared with $\mathrm{Tr}$ host and $\mathrm{Nr}$ donor fragments; the growth of these eyes closely paralleled that of the main orthotopic sample.

Screening and serial photography. Chimeras were reanesthetized between 18 and $36 \mathrm{hr}$ after surgery (stages 38-42) and examined (and photographed) through a dissecting microscope to evaluate the initial course of healing. Cases were excluded from the samples presented in Table 1 if (1) the graft had fallen out of the host wound, (2) the operated eye had altogether failed to develop, (3) the grafted fragment occupied less than one-third of the ocular circumference, or (4) alignment of graft and host fragments was judged to be poor enough to preclude apposition of graft and host retinal tissue.

At regular intervals extending to the time when subjects were killed, chimeras were anesthetized and rephotographed to provide a developmental history of pigmented and albino tissues for each eye. During midlarval life, beginning approximately at stages $49-50$, somc cases showed frank evidence of host-vs-graft rejection affecting pigmented ocular tissues. Such cases constitute the only additional material excluded from the samples presented in Table 1 .

Histology. Between stages 50 and 57 (Table 1), chimeric eyes were enucleated and fixed by immersion in Carnoy's fluid for $36 \mathrm{hr}$ before removing the lenses and embedding the eyes in paraffin. Serial sections were cut at a thickness of $8 \mu \mathrm{m}$ in a plane perpendicular to the optic axis. Sections were stained for $30 \mathrm{~min}$ in a $0.001 \%$ solution of quinacrine hydrochloride in sodium phosphate-citric acid buffer at $\mathrm{pH}$ 5.0. Following two $15 \mathrm{~min}$ washes in the same buffer, the sections were coverslipped with a $1: 1$ solution of glycerol and $0.1 \mathrm{~m}$ monobasic sodium phosphate adjusted to $\mathrm{pH} 4.0$.

Quantitation. All complete series of sections were digitized using a Leitz Dialux microscope fitted with epifluorescence illumination and an MDI microscope digitizer and allied software (Minnesota Diamet- 


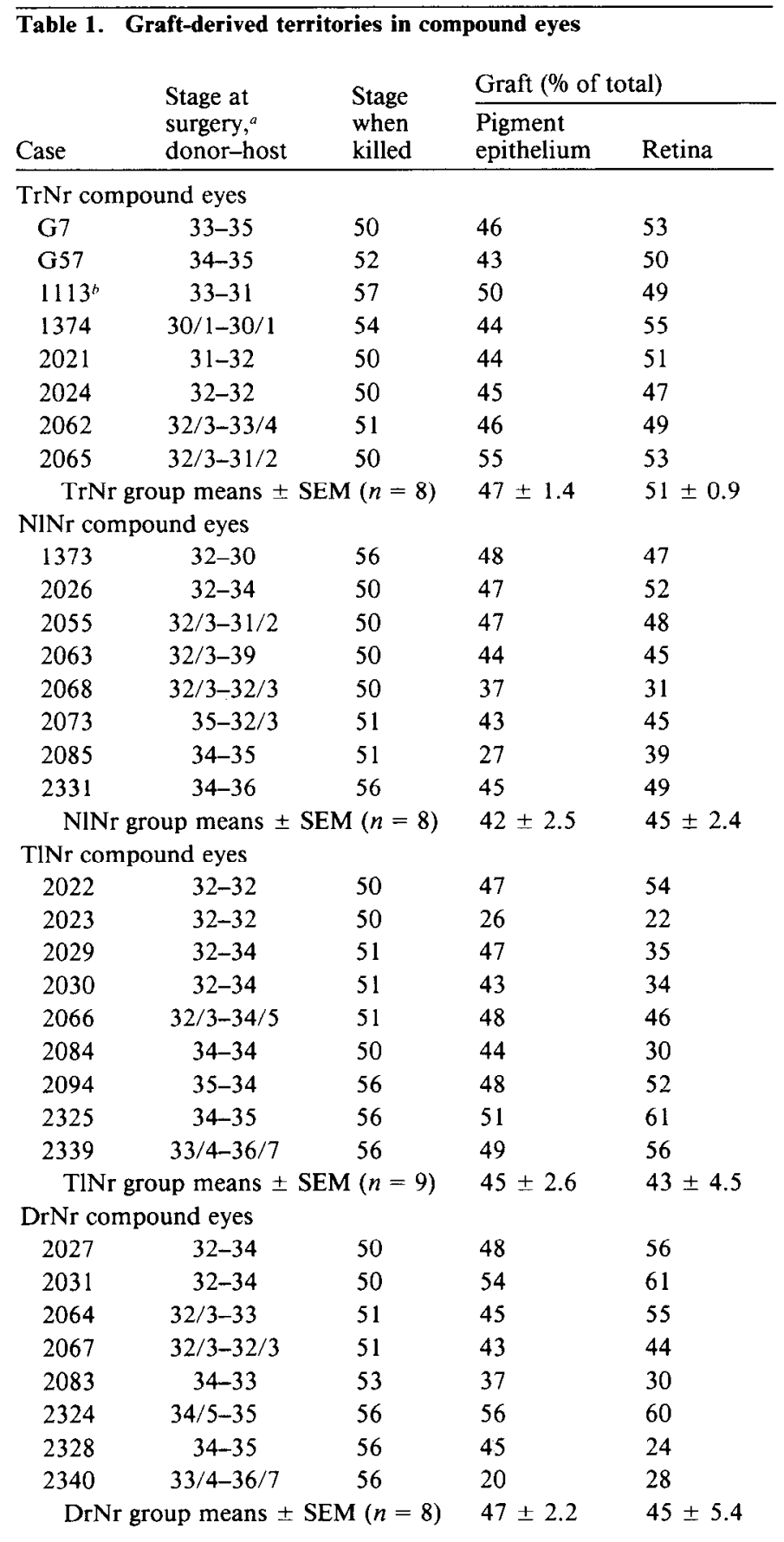

\footnotetext{
a Stage of embryos at the time of surgery.

${ }^{n}$ Case in which a nasal donor fragment was combined with a host temporal fragment.
}

\section{Results}

$\mathrm{X}$. borealis-X. laevis genetic marker system

Grafting pigmented $X$. borealis half-eyes into albino $X$. laevis hosts provided 2 independent markers for following the fate of graft-derived tissues. The contrasting pigmentation allowed grafted and graft-derived pigment epithelium to be visualized in the living animal with a dissecting microscope (Conway et al., 1980; Hunt et al., 1982). Upon preparation of quinacrinestained paraffin sections, the nucleoplasm of $X$. laevis cells, both neuronal and non-neuronal, was homogeneously stained by quinacrine, while all nuclei of $X$. borealis cells contained one or more flecks of intensely fluorescent material. Graft-host borders were easily defined in the neural retina (Fig. 2), and even single $X$. borealis cells within a $X$. laevis surround could be detected (cf. Fig. 12). Territories of graft- and host-derived germinal zone (at the extreme retinal periphery) were also clearly resolved, but the high nuclear density of the closely packed germinal cells produced a relatively high background fluorescence against which the nuclear flecks of single $X$. borealis cells might escape detection.

Except for anomalies of healing, the lamination of the ganglion cell layer, the inner plexiform layer, and the inner nuclear layer were smoothly continuous across graft-host boundaries. Subtle discontinuities were consistently evident in more external retinal layers. Compared to immediately adjacent or distant host-derived retina, graft-derived retinal territories were characterized by a slightly wider outer plexiform layer, more closely packed and more tightly laminated photoreceptor nuclei (Fig. $2, A, B)$, and longer and more robust photoreceptor outer segments (not illustrated). These differences were independent of the genotype of the pigment epithelium immediately underlying the graft-host retinal border.

The nuclear flecks in hybrids produced by mating $X$. borealis females to $X$. laevis males were less intensely fluorescent than those of $X$. borealis embryos (compare Fig. 2, $B$ and $C$ ). While this attenuation of signal did not compromise assignment of cell genotype under the microscope, it did make the production of clearly illustrative photomicrographs considerably more difficult. We found no differences in the fates of donor fragments prepared from hybrid and $X$. borealis embryos, and the 2 are not further distinguished in this report.

\section{Healing and growth of compound eyes}

During the first 24 postoperative hr, the graft-host borders of successfully healed cases were defined by concordant discontinuities of external ocular contour and pigmentation (Fig. 3A). These eyes were bilobate, with marked furrows interrupting the external ocular circumference at or near the dorsal and ventral extremes of the vertical meridian. The furrows separated a pigmented, temporal (graft-derived) sector from an albino, nasal (host-derived) sector. Pigmented sectors usually comprised less than half of the ocular circumference, probably because, for our stocks, embryonic $X$. borealis eyes were typically smaller than stage-matched $X$. laevis eyes.

Between 24 and $72 \mathrm{hr}$ after grafting, the initially bilobate appearance disappeared as the external contours of the eyes became rounder and smoother, and external graft-host boundaries were thereafter marked by contrasting pigmentation (Fig. $3 B$ ). The further growth of graft- and host-derived pigment sectors reflected the distributions of the 2 genotypes at the peripheral margin of the pigment epithelium, a finding consistent with previous observations that the pigment epithelium in the eye rics, St. Paul, MN) running on an Apple Ile computer. For every tenth section, 4 profiles were digitized: total pigment epithelium, graft-derived pigment epithelium, the vitreal surface of the neural retina, and the graft-derived ganglion cell layer and growth zone. Borders between graft- and host-derived ganglion cell territories were blurred by local cell mixing in some sections, but in most sections a clear distinction could be drawn between coherent zones of graft-derived ganglion cells, whose margins were taken to be the actual borders, and the occasional graft-derived ganglion cells that intermingled with host-derived ganglion cells on the "host side" of the border. 

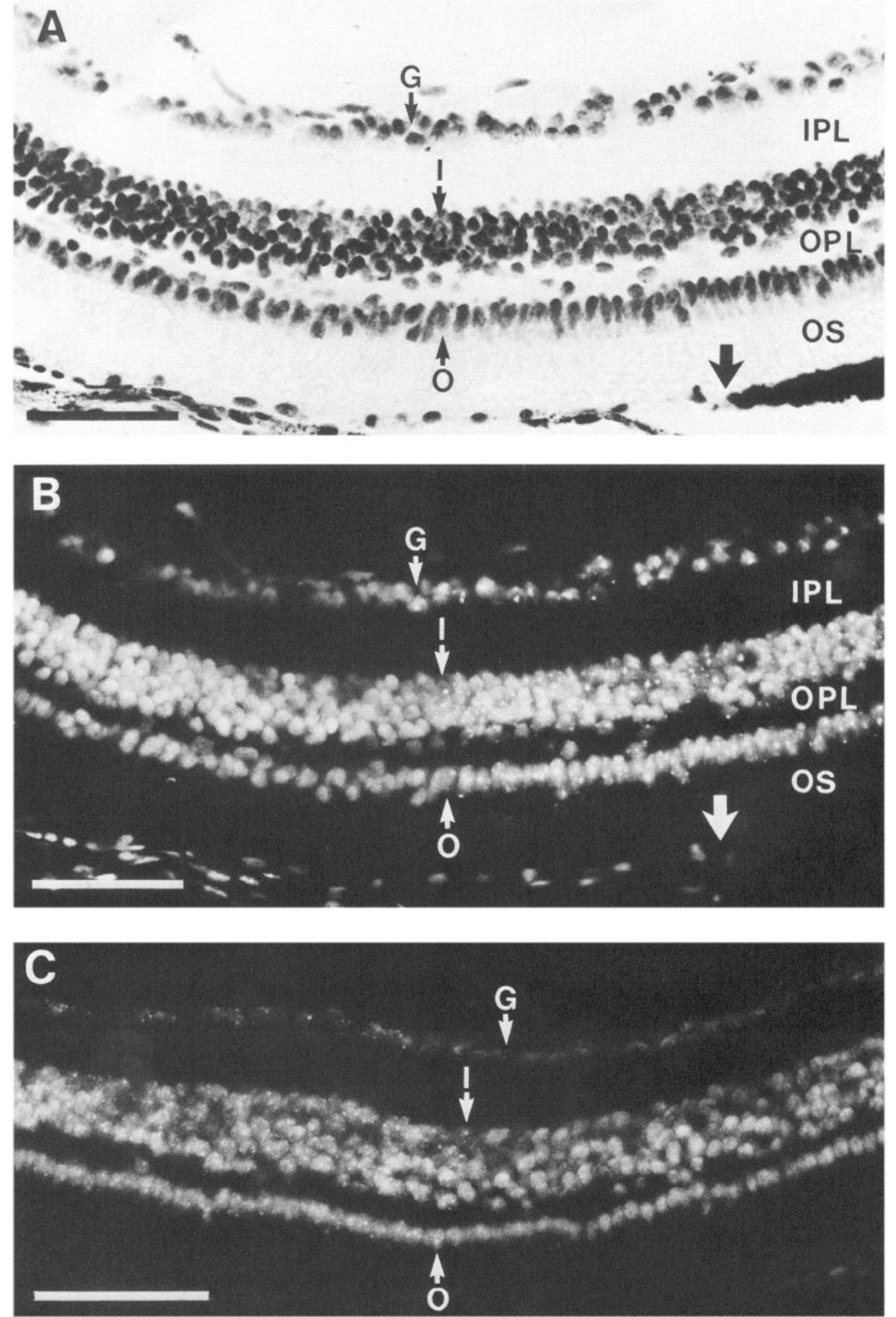

Figure 2. $X$. borealis-X. laevis marking system. A, Bright-field photomicrograph of a cresyl violet-stained section, taken in a plane perpendicular to the optic axis through the dorsal border of a heterotopic ( $\mathrm{DrNr}$ ) compound eye. $B$, The same field photographed under epifluorescent illumination after quinacrine staining. The large arrows at the lower right of $A$ and $B$ mark the position of the pigment epithelial graft-host border, with heavily pigmented $X$. borealis cells to the right and albino $X$. laevis cells to the left. The smaller arrows indicate the positions of graft-host borders in the ganglion cell $(G)$, inner nuclear $(I)$, and outer nuclear $(O)$ layers. When the quinacrine-stained section is examined at multiple focal planes all $(X$. borealis) cells to the right of these borders contain one or more flecks of intensely fluorescent material, even though at the single focal plane of this micrograph some $X$. borealis neurons appear unmarked. Other abbreviations: $I P L$, inner plexiform layer; $O P L$, outer plexiform layer; $O S$, photoreceptor outer segments. $C$, Quinacrine-stained section through the ventral border of a heterotopic (DrNr) compound eye in which the donor fragment was taken from a $X$. borealis-X. laevis hybrid. The nuclear flecks, visible in the hybrid cells to the left of the indicated retinal borders, are considerably less intense than those in $X$. borealis nuclei; the photomicrograph was deliberately printed darker for optimal visualization of the reduced signal. Scale bars, $50 \mu \mathrm{m}$. 

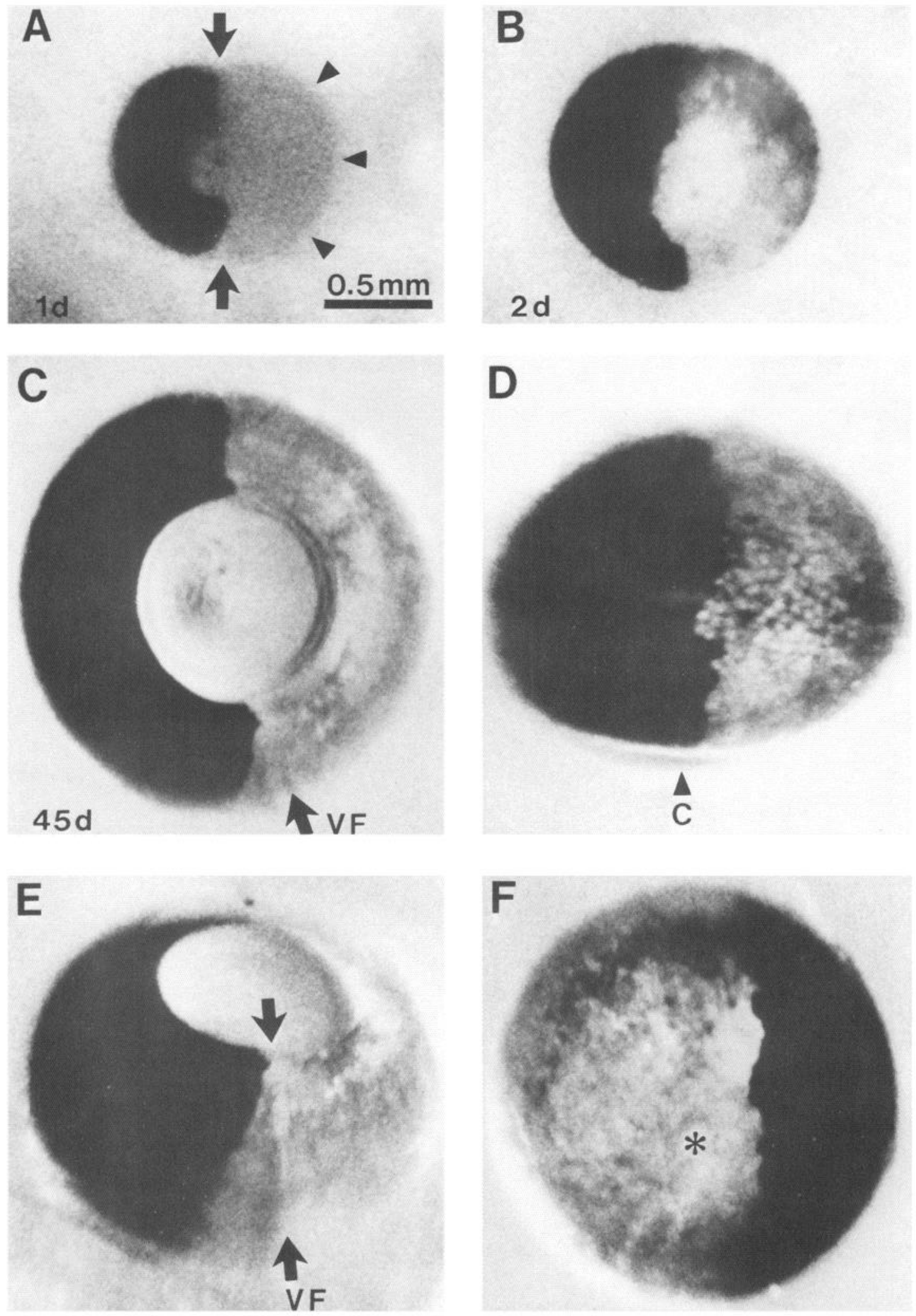

Figure 3. Growth of a single orthotopic compound eye, presented at the same magnification in optic axis views $(A, B, C)$ at 1,2 , and $45 \mathrm{~d}$ after surgery. The $45 \mathrm{~d}$ stage is shown in dorsal, ventral, and rear eye views in $D, E$, and $F$. Arrowheads in $A$ outline the nasal albino host ocular fragment; the 2 arrows mark the positions of healing furrows between the host fragment and the heavily pigmented temporal donor fragment. In $D$, the dorsal graft-host pigment border runs as a straight, albeit somewhat ragged, line from the back to the front of the eye (top to bottom; VF, ventral fissure; $c$, cornea). In $E$ the ventral pigment border is initially displaced from the ventral fissure (running between the arrows) but approaches the fissure closely at the front of the eye. In $F$, the pigment border at the back of the eye is temporally displaced from the optic nerve head (asterisk). 

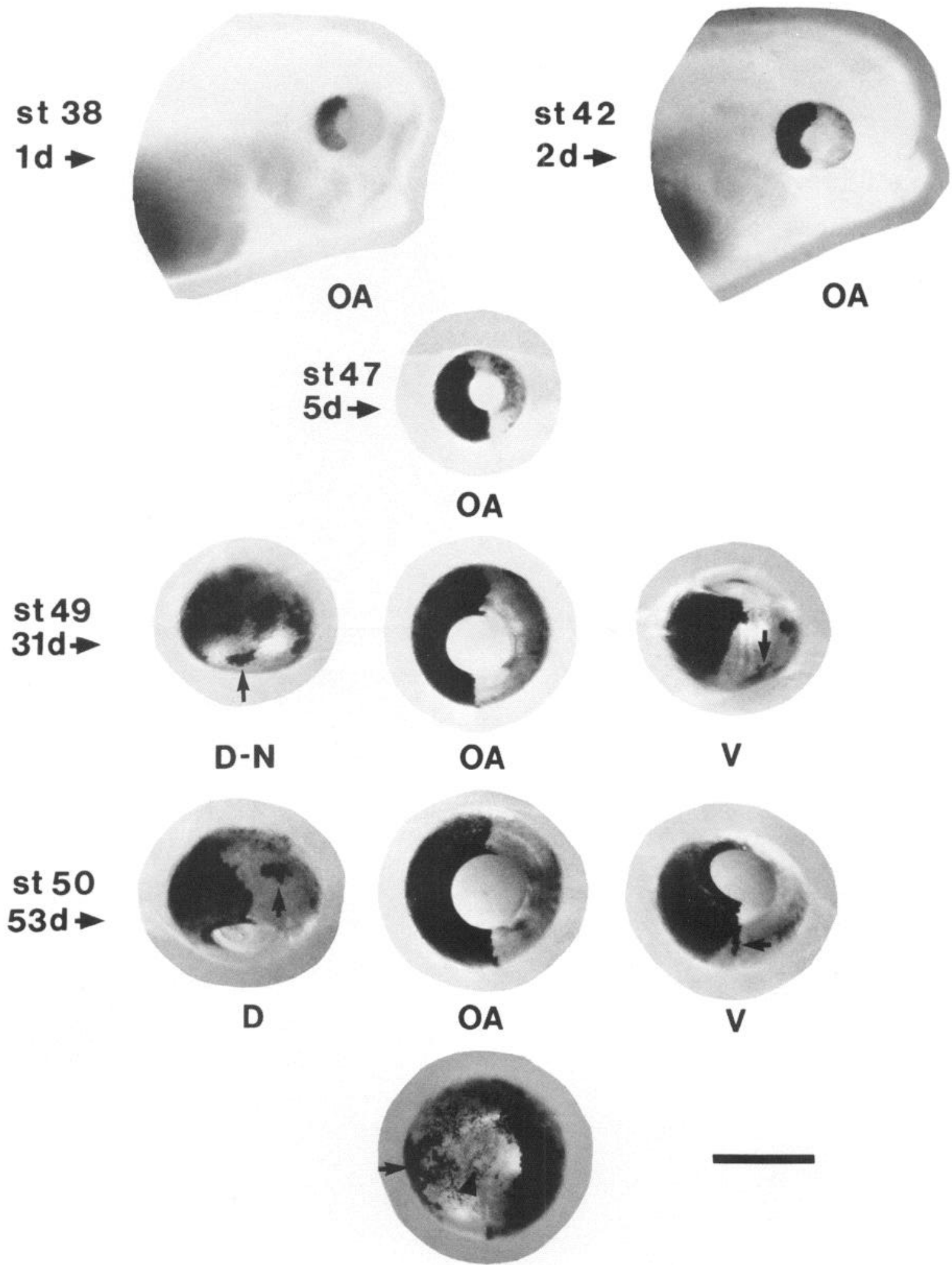

D

\section{BOE}

Figure 4. Serial photomicrographs of the external surface of an orthotopic compound eye at different developmental stages. In this and Figures 6,8 , and 10 , the stage of development $(s t)$ and the age in days (d), is indicated to the left of each group of micrographs, and the angle of view is indicated by the letters beneath each ( $O A$, optic axis; $D$, dorsal; $N$, nasal; $T$, temporal; $V$, ventral; $B O E$, back of eye, with nasotemporal reversal relative to other micrographs). At stages 38-47, temporal graft-derived pigment epithelium occupied less than $50 \%$ of the ocular surface, but by stage 49 it had expanded to occupy roughly $50 \%$ of the ocular circumference at the front of eye. At stage 50 , the expansion of the graft-derived territory was clearly evident in the temporal-to-nasal course of both dorsal and ventral borders (from the back to the front of the eye). Beyond stage 50 , irregularly shaped clumps of heavily pigmented, graft-derived choroid were visible in nasal regions (some indicated by arrows). At the back of the eye, the graft-host border was displaced temporally from the optic nerve head (arrowhead). Scale bar, $0.5 \mathrm{~mm}$ (all micrographs). 

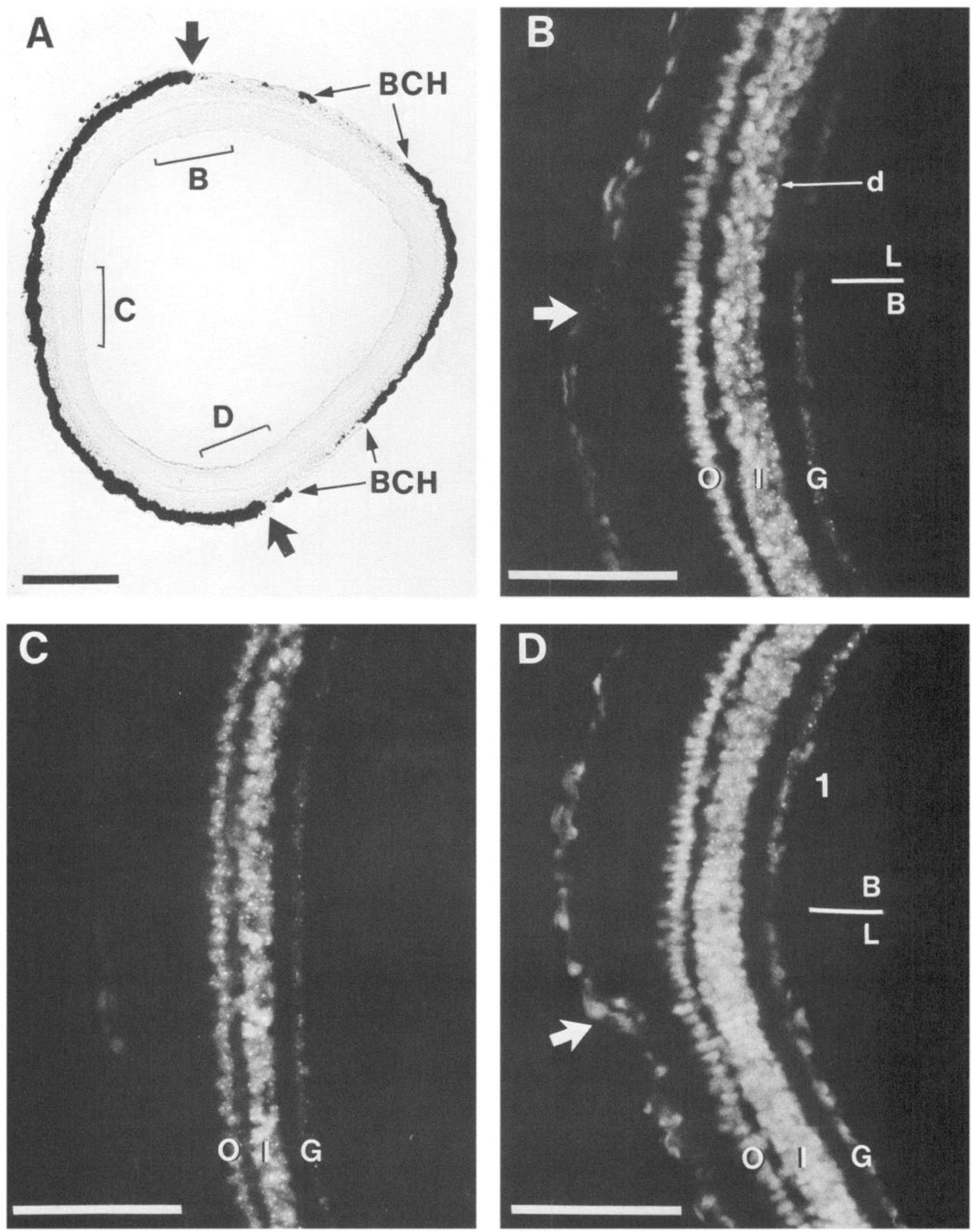

Figure 5. Photomicrographs of a single section through the equatorial region of the orthotopic compound eye presented in Figure 4. A, L. magnification view of the unstained section. The dorsal (top $)$ and ventral (bottom) borders between temporal, graft-derived, pigmented (to the left), and nasal, host-derived, albino (to the right) pigment epithelium are marked by large arrows. Pigmented tissue within nasal regions is graft-derived choroid $(B C H) . B-D$, Fluorescence photomicrographs of the retinal areas within the brackets in $A$, after staining with quinacrine. The horizontal lines at the vitreal retinal surface in $B$ and $D$ indicate the level of the border between $X$. borealis $(B)$ and $X$. laevis $(L)$ neurons; the large arrows indicate the pigment epithelial borders, which in this case correlated quite closely with the retinal borders. At the dorsal border $(B)$, a single $X$. 
of Xenopus grows through addition of cells at its distal margin near the front of the eye (Conway et al., 1980). Small irregularities in the profiles of graft-host pigment borders, situated just proximal to the growth zone in young compound eyes, were preserved over many weeks of growth and severalfold increases in ocular diameter, but became ever more displaced from the growth zone by subsequently generated tissue.

The initial growth of compound eyes was accompanied by minor modifications of the pigmentation template established during the first 72 postoperative hrs. Consistently, the slightly smaller graft fragments expanded during growth and came to subtend a larger fraction of the ocular circumference at the front of the eye by midlarval stages $48-52$ (Figs. $3,4,6,8,10$ ). When the eye was removed from the host and viewed from the back, the curvature of the pigment boundary reflected the asymmetric starting configuration and the subsequent expansion of graftderived tissue (Fig. $3 E$ ). One common variation in this general pattern of pigmentation occurred when graft-derived melanogenic cells formed irregular patches of heavily pigmented choroid that could overlie both graft- and host-derived pigment epithelium (Figs. 4-6).

The progression of graft integration and growth within the neural regina, while inaccessible to direct observation, could be inferred by comparing neural graft-host borders to those in the overlying pigment epithelium. Beyond stage 32 , the neural retina, like the pigment epithelium, grows through the addition of cells at its peripheral margin (Jacobson, 1968b, 1976; Hollyfield, 1971; Straznicky and Gaze, 1971). This has also been shown for compound eyes (Straznicky and Tay, 1977; Beach and Jacobson, 1979). Neurons generated at successively later ages occupy successively more peripheral retinal addresses.

In most orthotopic and heterotopic compound eyes, graftderived neurons occupied an undivided expanse of temporal retina extending between the dorsal and ventral midlines, and from a point near the optic nerve head to the retinal periphery (Fig. 5). Retinal lamination across graft-host borders near the optic nerve head, in the oldest part of the retina, often provided evidence of inexact surgical apposition of graft and host fragments. The same kinds of laminar defects were observed in chimeric eyes examined after growth to developmental stages $50-56$, suggesting that, once formed, perturbations of retinal lamination persisted and provided a means for assessing initial graft integration. The most typical defects consisted of small, spherical rosettes of cells within graft segments, abrupt laminar shifts or faults in a direction perpendicular to the plane of the retina, ectopic cells (presumably neurons, usually of graft origin) within the inner or outer plexiform layers or external to the outer nuclear layer, and focal thinnings of either graft or host retina. Most of these integration defects became progressively less distinct and eventually disappeared in a succession of more peripheral sections spanning about $100 \mu \mathrm{m}$ of the proximodistal retinal axis. More flagrant healing anomalies were present in a minority of cases and some of these were occasionally perpetuated distally through a large fraction of the retina.

\section{Quantitative analyses}

Table 1 presents estimates of the relative areas occupied by graftand host-derived retina and pigment epithelium in orthotopic and heterotopic compound eyes. Only those eyes whose initial course of healing met the criteria discussed in Materials and Methods were included in the data in this table.

Sample means for the percentage of retina occupied by graftderived neurons fell within a relatively narrow range (43-51\%). The mean of the orthotopic sample was larger than that of all 3 heterotopic samples, but only the difference between the $\mathrm{TrNr}$ and NINr samples reached even marginal significance $(p<0.05$; Student's $t$ test). The variability of graft-derived territories in each of the heterotopic samples was clearly greater than that of the orthotopic sample ( $p<0.005$ for each comparison). Results for the pigment epithelium paralleled those for the retina, but there was less variation within and between samples. The correlation between the proportions of graft-derived pigment and retinal tissues in individual cases was close but inexact, a finding anticipated by the appearance of sectioned material in which graft-host borders in the 2 tissues were rarely in precise register.

Additional orthotopic and heterotopic cases whose initial external appearance precluded inclusion in the main quantitative sample were nevertheless examined carefully. Within this sample, there was more variation in the extent of graft-derived neural retina, ranging from a low of $15 \%$ in a case where the grafted fragment was judged to occupy only $25 \%$ of the initial ocular circumference, to a high of approximately $70 \%$ in an eye with a major healing anomaly. In general, the territories of graftderived retina and pigment epithelium were less tightly correlated with one another. For instance, $50 \%$ of the pigment epithelium showed $X$. borealis pigmentation in the case in which only $15 \%$ of the neural retina was graft-derived. Nevertheless, all of these eyes showed a continuous graft-derived sector of neural retina that extended from a point abutting or close to the optic nerve head all the way out to and into the germinal neuroepithelium at the periphery of the retina.

\section{Qualitative variations}

The features of compound eye growth described to this point are those typical of the major part of our sample; we have focused on the principal finding that both orthotopic and heterotopic placements of graft fragments led to the generation of large and coherent territories of graft-derived retina and pigment epitheleium at late larval stages (Fig. 5). However, both orthotopic and heterotopic samples included variations on this general theme.

The NINr eye presented in Figures 6 and 7 illustrates the generation of cell files in both retina and pigment epithelium by "surgical accident." When the subjects were killed, tissues showed large, coherent temporal territories and smaller, ventral stripes of graft-derived cells. Three days after surgery a small protrusion of graft-derived pigment epithelium was apparent at the ventral margin of the main pigment mass. This enlarged into a separate stripe of pigment that elongated in step with further ocular growth (Fig. 6). The homologous retinal stripe also extended from a point near the optic nerve head to the germinal neuroepithelium at the front of the eye (Fig. 7). Our interpretation of this pattern is that the ventral margin of the graft fragment was damaged during implantation, and produced a small secondary graft fragment that healed in place and generated the secondary stripes of graft-derived tissues.

borealis cell $(d)$, displaced by $4-5$ cell diameters from other borealis cells, is prescnt along the inner surface of the inner nuclear layer $(l)$. The entire temporal retina was populated by graft-derived neurons $(C) . G, O$, Ganglion cell and outer nuclear layers. Scale bars, $100 \mu \mathrm{m}(A) ; 50 \mu \mathrm{m}(B-D)$. 


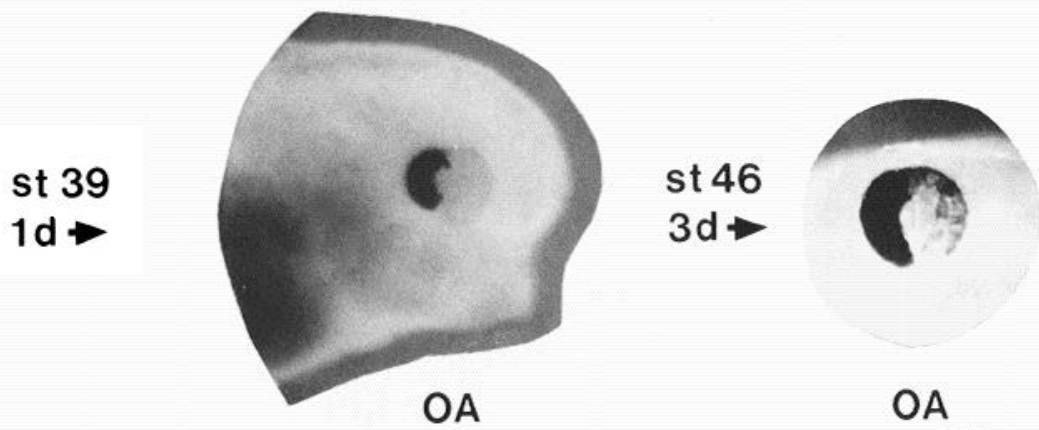

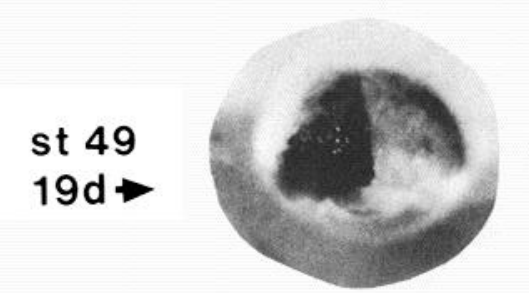

D

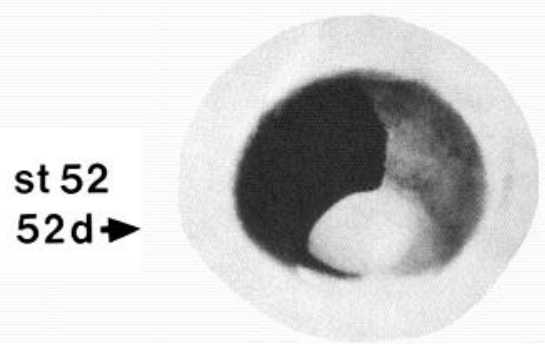

D

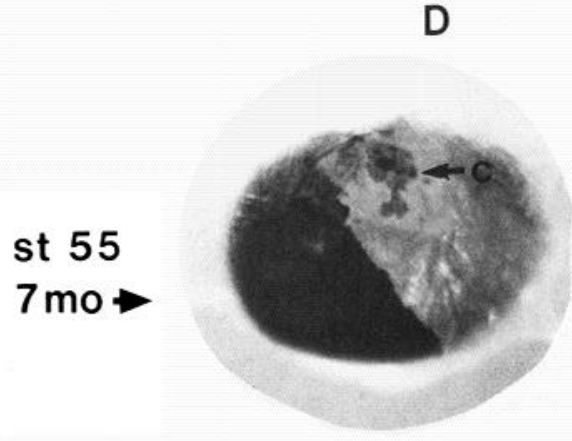

D

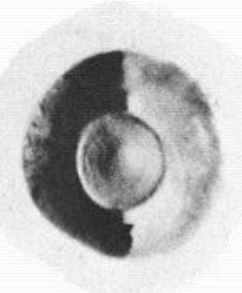

$O A$

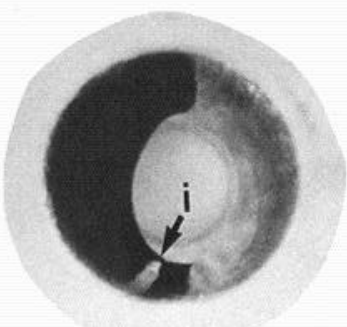

OA

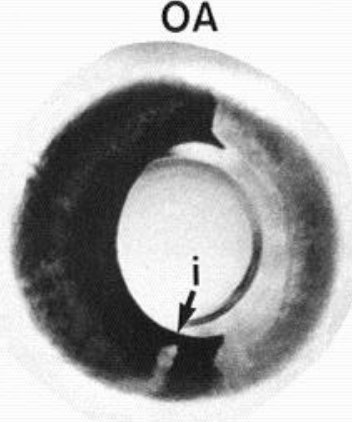

OA

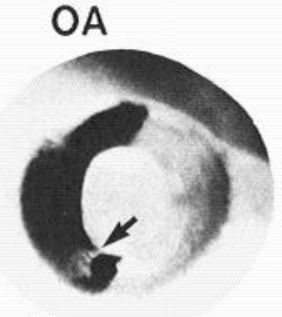

OA
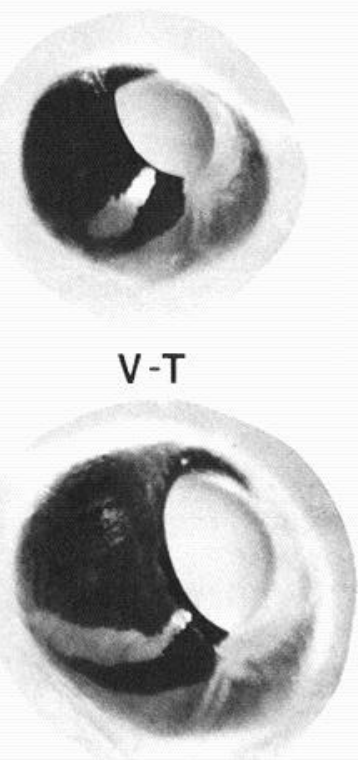

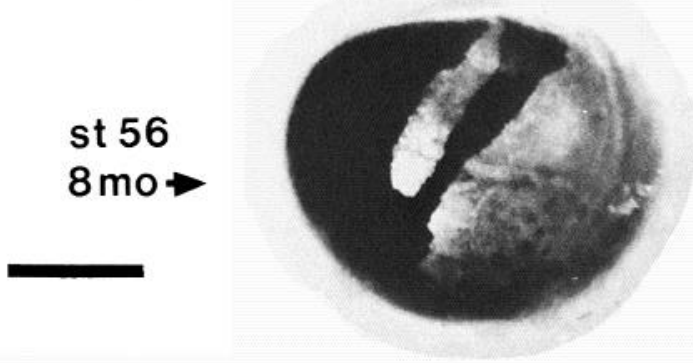

BOE-V
V-T

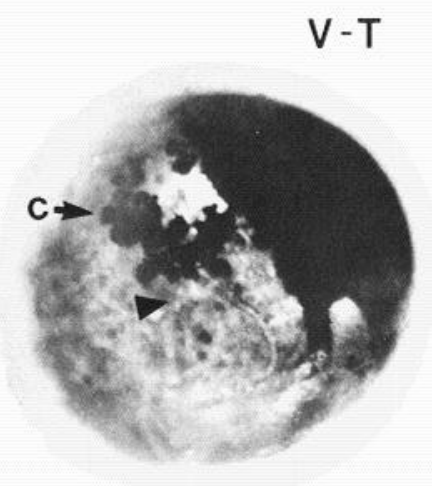

BOE

Figure 6. Serial photomicrographs of the growth of a single NINr eye. The asymmetric starting configuration evident at stage 39 was reversed during early growth; by stage 49 , graft-derived pigment epithelium had expanded to occupy nearly $50 \%$ of the ocular circumference at the front of the eye. At stage 49, a narrow band of host tissue (arrow, right $O A$ view) separated the main temporal graft-derived territory from a smaller band of graft-derived pigment epithelium. This narrow ventral band continued growing as a separate territory even though, after stage 52 , graft-derived iris cells ( $i$ in $O A$ at st 52 and 55) spanned the interruption of graft-derived pigment epithelial cells. The origin of the ventral pigmented band as a branch of the main graft-derived territory was apparent in the BOE micrographs taken after enucleation at stage 56 . Some graft-derived, pigmented choroidal tissues $(c)$ were present just dorsal to the optic nerve head (arrowhead). Other abbreviations as in Figure 4 . Scale bar, $0.5 \mathrm{~mm}$. 

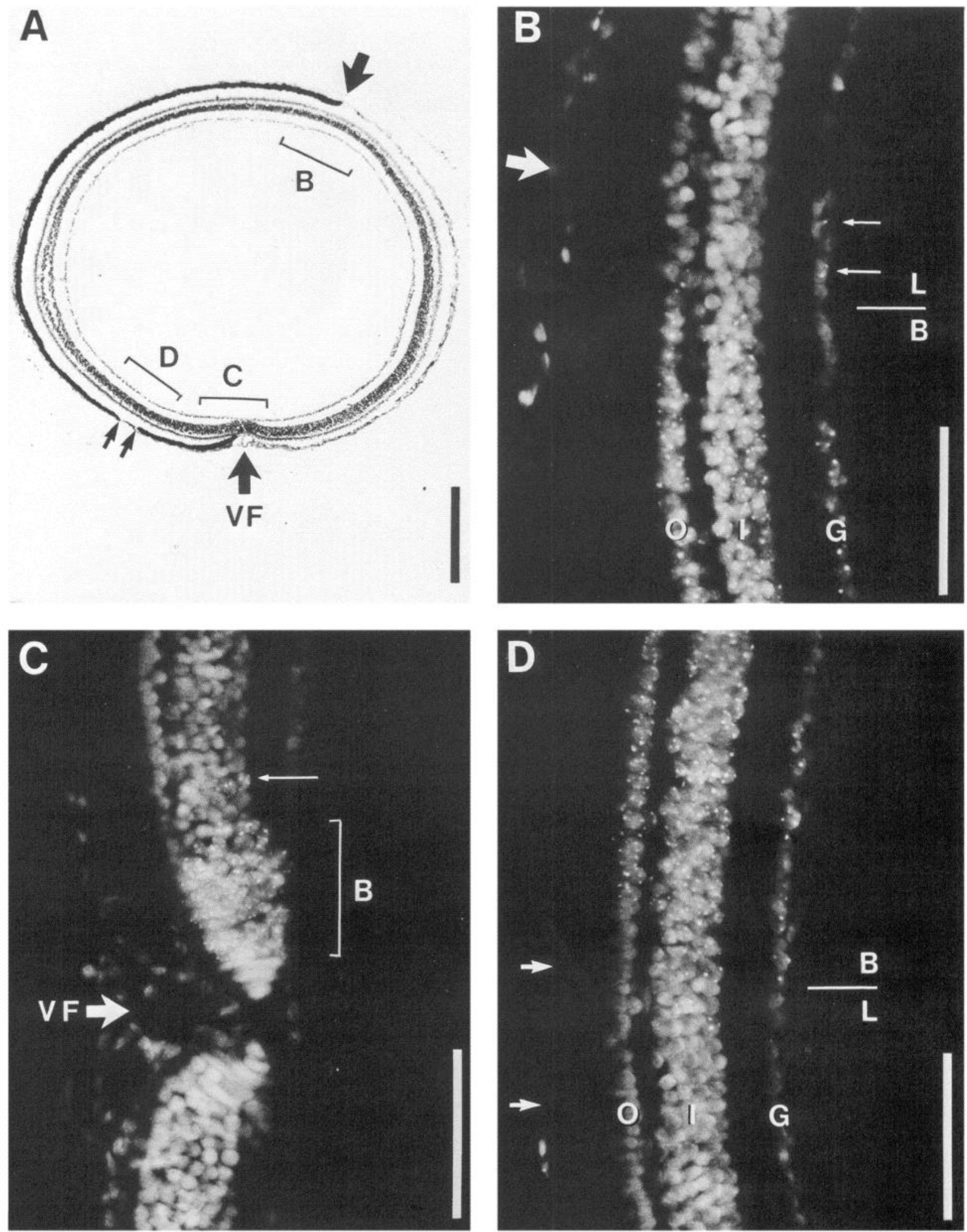

Figure 7. Photomicrographs of a section through the front of the NINr compound eye presented in Figure 6. A, Low-power micrograph of the section after cresyl violet staining. The dorsal pigment epithelial graft-host border is indicated by an arrow, the ventral border is indicated by the arrow at $V F$. The pair of small arrows delimit the narrow sector of host-derived albino pigment epithelium intercalated between sectors of graftderived pigment epithelium. $B$, The dorsal graft-host borders in the inner $(I)$ and outer $(O)$ nuclear layers were reasonably well aligned (at the level of the horizontal line at the vitreal surface). A continuous sector of graft-derived ganglion cells $(G)$ ended slightly temporal to these borders but 2 additional $X$. borealis cells (small arrows) were present within "host territory." $C$, A narrow band of $X$. borealis cells (delimited by the bracket) was present just temporal to the VF. Two additional $X$. borealis cells were isolated from the main band (small arrow). $D$, The horizontal line indicates the level of the graft-host border in the ganglion cell layer and at the inner surface of the inner nuclear layer. The border in the outer nuclear layer was displaced temporally, and there was considerable local cell mixing in the inner nuclear layer. Scale bars, $200 \mu \mathrm{m}(A) ; 50 \mu \mathrm{m}$ $(B-D)$. 

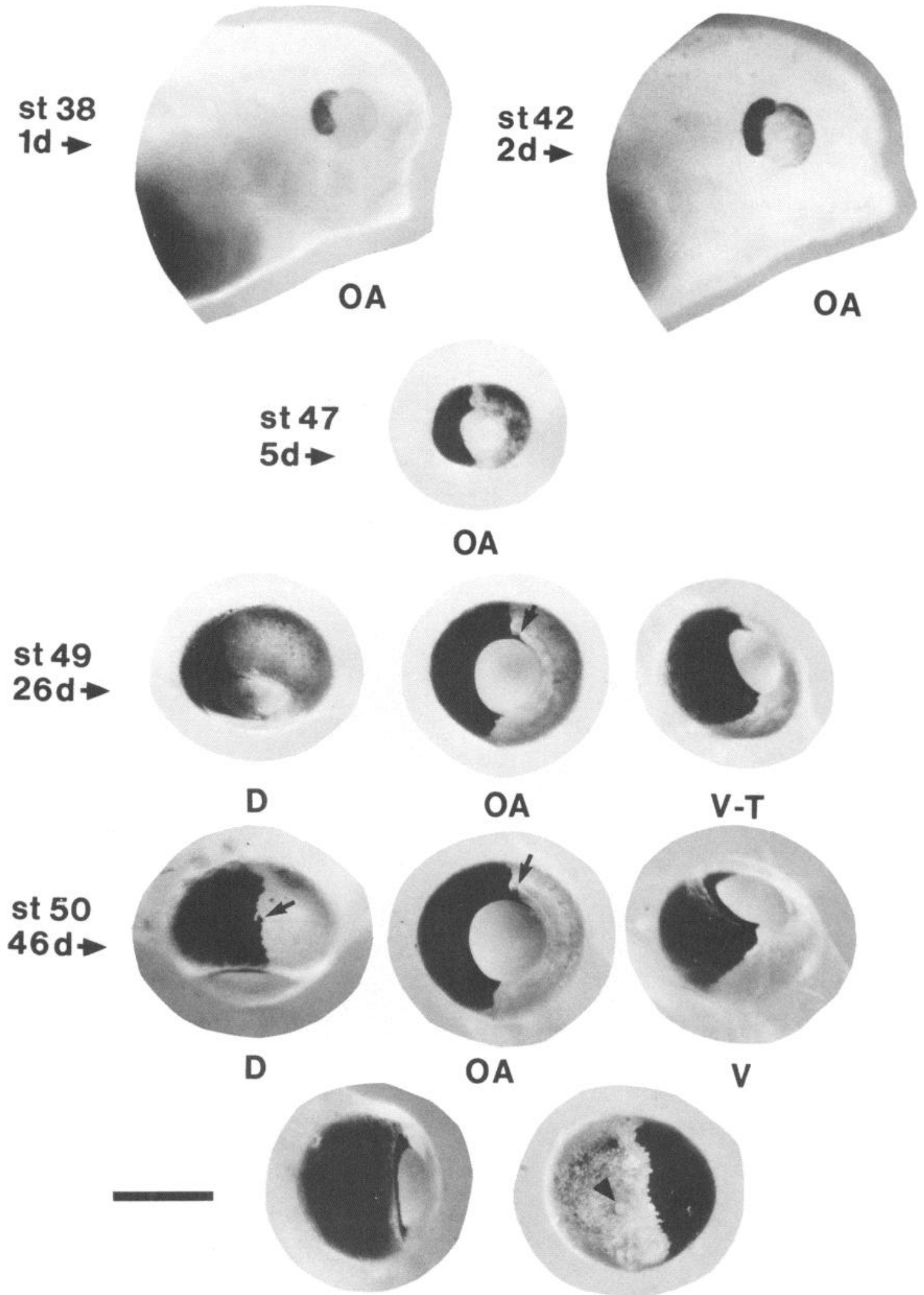

OA

V
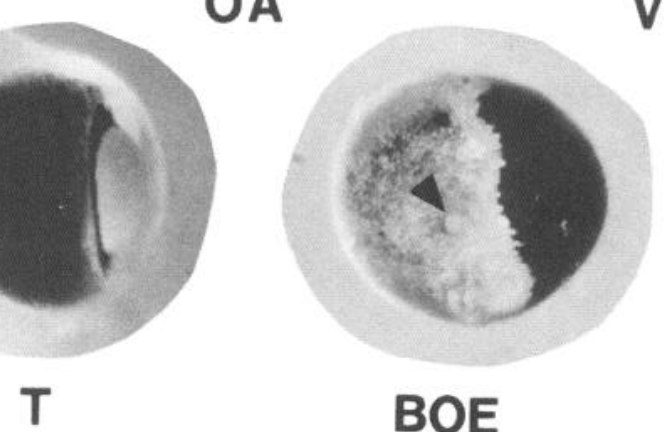

BOE

Figure 8. Serial photomicrographs of a single TINr eye. At stage 38, the graft-derived pigment epithelium occupied roughly $30 \%$ of the ocular surface, but expanded during growth to occupy close to $50 \%$ of ocular circumference at the front of the eye by stages 50 . At stages 49 and 50 , a nasal expansion of the pigment epithelium at the dorsal border produced several fine files of graft-derived cells (not visible in these micrographs) extending towards the back of the eye as a fine fringe emanating from a clump (arrows in OA views, 49 and 50) of pigmented tissue near the growth zone. A similar, earlier expansion produced the short side-file of pigmented tissue visible in the dorsal view at stage 50 (arrow). Other labeling as in Figure 4. Scale bar, $0.5 \mathrm{~mm}$. 

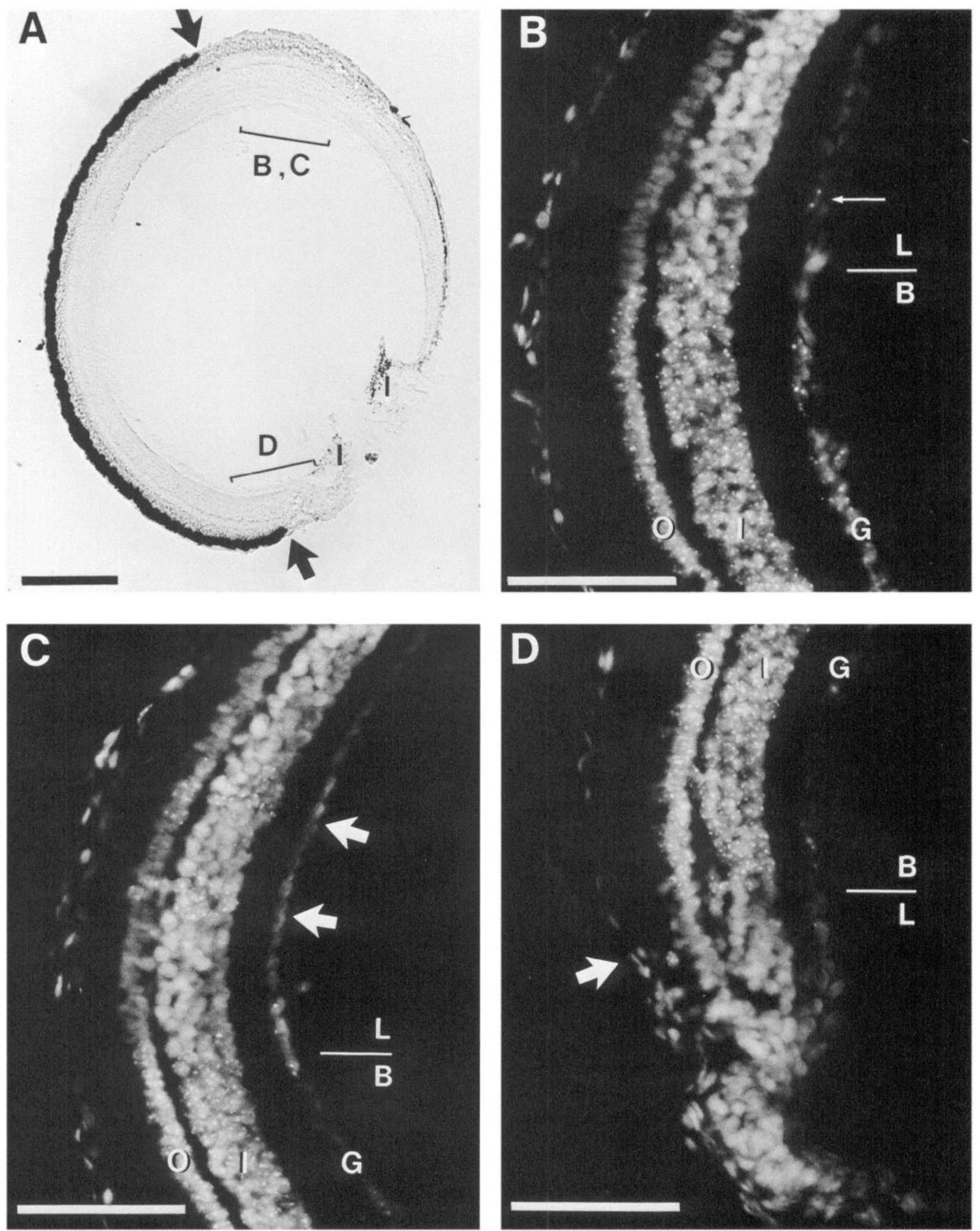

Figure 9. Photomicrographs of sections through the front of the $\mathrm{TINr}$ compound eye illustrated in Figure 8 . The section presented in $A, B$, and $D$ passes through (host-derived) ventronasal iris $(I$ in $A)$. Other labeling conventions as in Figures 5 and 7 . The dorsal and ventral retinal borders are presented in $B$ and $D$; at the dorsal border a single displaced $X$. borealis cell was present within the ganglion cell layer (small arrow, $B$ ). $C$, The dorsal border region from a section approximately $50 \mu \mathrm{m}$ closer to the front of the eye. Two narrow files of graft-derived cells, not present at the level shown in $B$, are indicated by the arrows at the vitreal surface. Scale bars, $100 \mu \mathrm{m}(A) ; 50 \mu \mathrm{m}(B-D)$. 

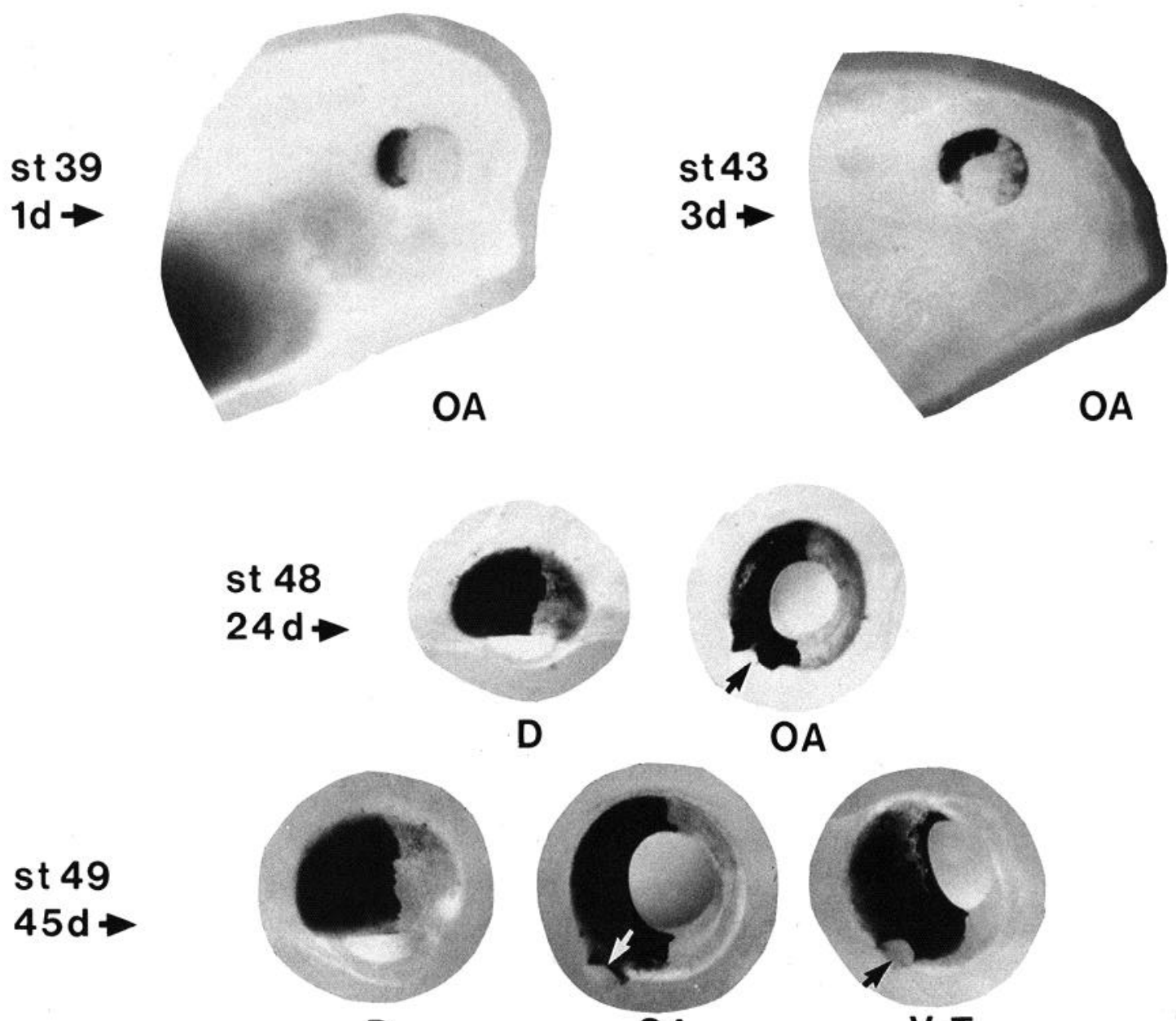

D

OA
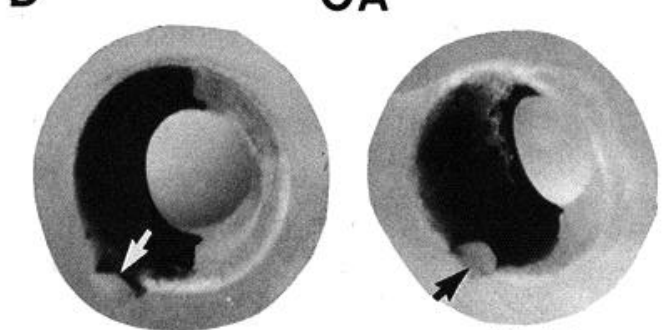

D
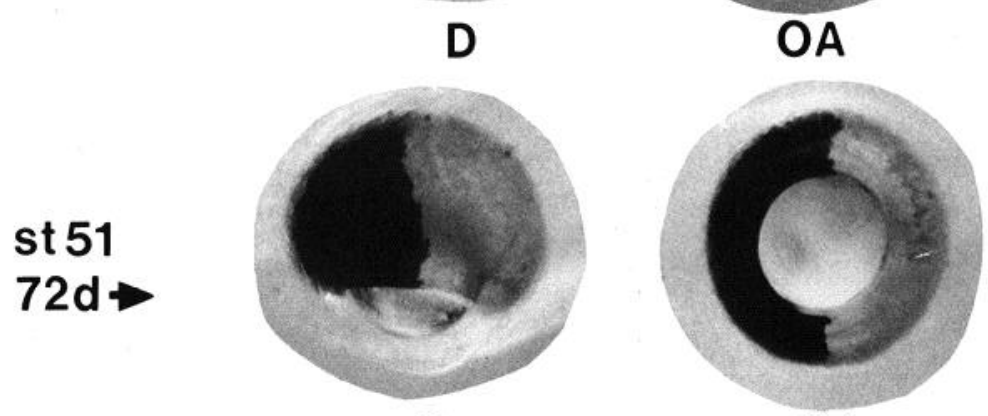

D
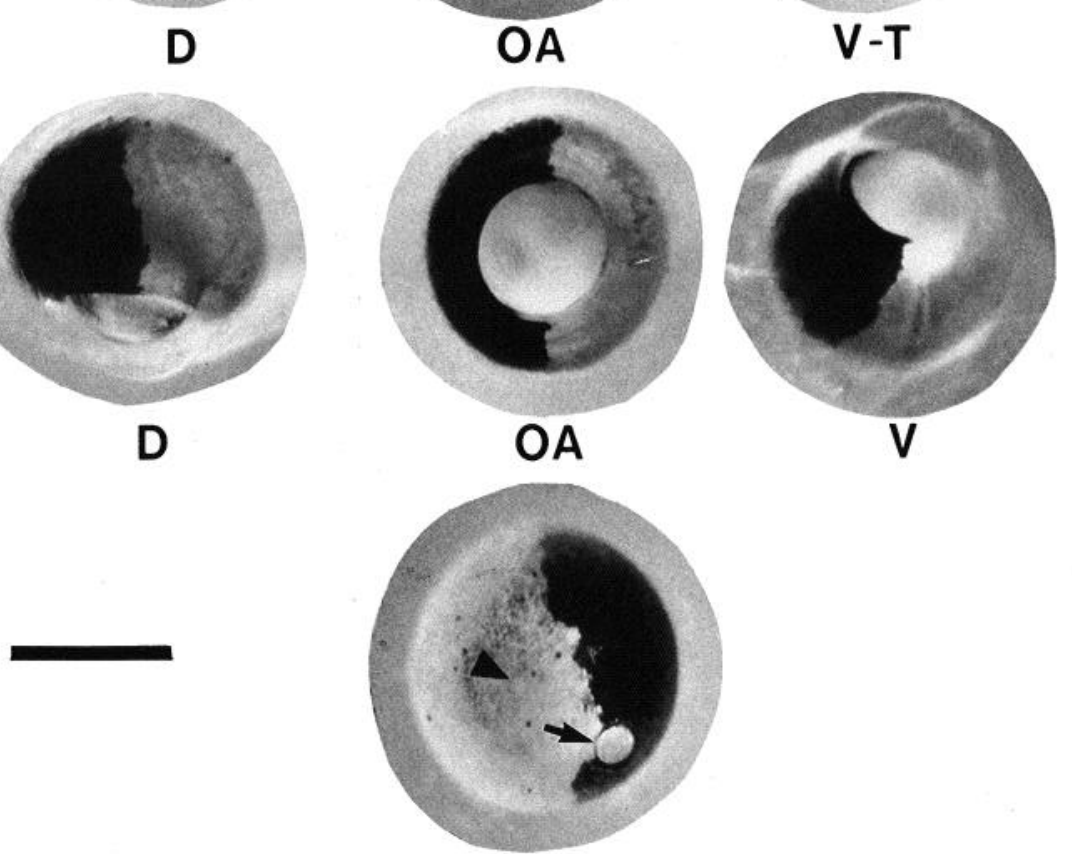

BOE

Figure 10. Serial photomicrographs of a single DrNr compound eye. By stage 48, an adhesion had developed between graft-derived tissues and the host's orbital bed (arrows, st 48-51). This defect was displaced ever further from the front of the eye by smoothly continuous graft-derived pigment epithelium generated during subsequent growth of the eye; by stage 51 it was no longer visible in OA views, but occupied a position (arrow) near the optic nerve head (arrowhead) in BOE views after enucleation. As in other cases, the initially small graft-derived territory seen at stage 39 rapidly expanded to occupy approximately $50 \%$ of the ocular circumference at the front of the eye by stage 48 . Other abbreviations as in Figure 4. Scale bar, $0.5 \mathrm{~mm}$. 

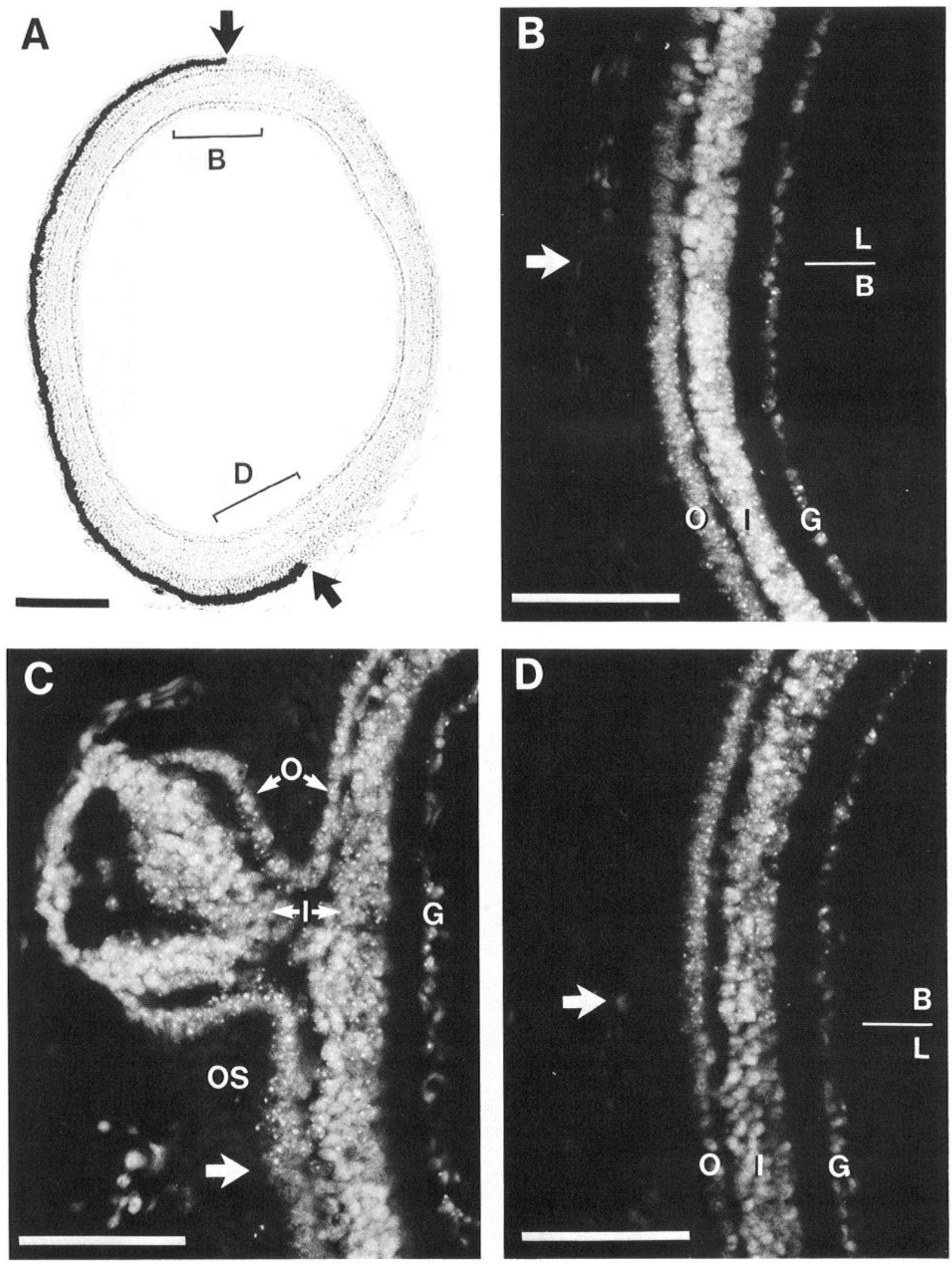

Figure 11. Photomicrographs of a section through the equatorial region of the DrNr compound eye illustrated in Figure 10. Labeling conventions follow those of Figures 5 and 7. $A$, Low-power micrograph of unstained section. $B$ and $D$, Fluorescence micrographs of dorsal and ventral grafthost borders in the neural retina. $C$, Ventral retinal border zone, as seen in a section approximately $100 \mu \mathrm{m}$ closer to the back of the eye. The grafthost border is indicated by the large arrow near the bottom of the micrograph. A large bleb, representing outpocketings of graft-derived cells from the inner $(I)$ and outer $(O)$ nuclear layers was present immediately within the graft-derived retinal territory. The ganglion cell layer $(G)$ was smoothly continuous in the area of the defect in the outer retinal layers. Scale bars, $100 \mu \mathrm{m}(A) ; 50 \mu \mathrm{m}(B-D)$. 
The TINr eye shown in Figures 8 and 9 illustrates the generation of cell files in the pigment epithelium and neural retina by alterations of the germinal template at the front of the eye. Just prior to death, graft-derived pigment cells at the front of the eye extended nasally from the principal temporal graft-derived territory, mixed with host cells, and, during further growth, generated fine trailing files of pigmented cells within a host surround (Fig. 8). In an unusual concordance between retina and pigment epithelium in the fine details of growth patterns, the neural retina of this eye also showed narrow, graft-derived cell files near the dorsal graft-host border at the front of the eye (Fig. 9C). They were continuous with narrow independent files of graft-derived germinal neurocpithclium within the growth zone, and extended slightly further towards the back of the eye than did the homologous pigment files, suggesting that they formed somewhat earlier during the eye's growth.

The DrNr case presented in Figures 10 and 11 illustrates that even relatively major anomalies of healing were often resolved during growth of compound eyes. The initial course of graft integration in this case appeared to be unremarkable, but by stage 48 an adhesion had developed between the eye and the orbital bed. This eventually became a porthole-like defect within the graft-derived pigment epithelium near its ventral border with host tissue. The defect was resolved before the end of stage 48 , whereafter the graft-derived pigment epithelium grew as a smoothly continuous sector. Within the neural retina, lamination was normal in proximal regions. At the site of the pigment epithelial defect, the inner and outer nuclear layers within the graft-derived segment and just temporal to the ventral grafthost border bulged out toward the external surface of the eye to form a bleb of laminated retinal tissue connected by a stalk to the surrounding, normally laminated retina (Fig. 11C). As for the pigment epithelium, the retinal defect was also quickly resolved, and retinal structure in more peripheral sections appeared normal (Fig. 11D).

\section{Graft-host border configurations in the neural retina}

While graft-host borders extended cleanly across all 3 nuclear layers of the retina in many sections of all compound eyes (Figs. $2, B, C ; 11, B, D), 3$ variations of this pattern were common.

Graft-host borders often occurred at slightly different circumferential positions in different retinal laminae, one or another lamina extending further into host territory than the other. The misregistration of borders among retinal laminae was clearly apparent in sections taken in a plane perpendicular to both the retinal surface and to the graft-host border, and was therefore not an artifact attributable to the plane of sectioning. In the most typical form of misregistration, there was a steplike progression from the internal to the external retinal laminae. More rarely, only one lamina was out of register with the other 2 . The pattern of registration and misregistration along a single border often alternated among various forms at different levels of the proximodistal retinal axis.

Local cell mixing, a fine-grained intermingling of graft- and host-derived cells over distances of one or a few cell diameters, was observed in all cases. For example, quite commonly a 4or 5-cell-diameter wide segment of the ganglion cell layer between the coherent territories of graft- and host-derived ganglion cells would contain a mixture of the 2 different genotypes (Figs. $7 B, 9 B)$. Local cell mixing was also common in the inner nuclear layer, where it made the border in that layer appear somewhat fuzzy (Fig. $7 D$ ). By contrast, graft-host borders in the outer nuclear layer were usually defined with precision; although examples could be found, only rarely was a photoreceptor cell isolated from other members of its genetic cohort by even a single cell diameter.

The third principal variation was the occurrence of displaced cells, single cells that were isolated by more than 5 cell diameters from other members of their genetic cohort in the same lamina and which did not appear to be members of an independent cell file (Fig. 12). The laminar distribution of such cells was highly stereotyped. They were most common in the ganglion cell layer and were found with nearly equal frequency along the inner surface of the inner nuclear layer, but they were far less common at other levels of the inner nuclear layer. Displaced cells, clearly distinguishable by nuclear morphology from photoreceptor cells, were also found within the outer plexiform layer, often apposed to the outer surface of the inner nuclear layer. As mentioned above, graft-host borders in the outer nuclear layer were sharp, and displaced photoreceptors were not observed.

\section{Rejection of graft-derived tissues}

A portion of the interspecific compound eyes prepared for this series, including some in which hybrid donor tissue was used, showed evidence of what we have interpreted as immunological rejection of graft-derived tissues by the host. Tissue loss was either confined to the pigment epithelium or, in those cases with retinal involvement, was far more advanced in the pigment epithelium than in the retina. Very little evidence of rejection was seen in larvae before stage 48 , and most severe reactions had commenced bedore stage 54 .

Rejection that had progressed to the point of substantial cell loss in the pigment epithelium was detectable in the living animal. The margins of graft-derived pigment epithelial territories appeared to be eroded. Additionally, the choroid developed a speckled appearance as pigmented debris originating from graftderived pigment epithelium was dispersed through both graft and host choroidal tissucs. Histological examination of cases with clearly established rejection confirmed the presence of pigmented debris within choroidal tissues. In a subset of these cases, intraretinal pigment was observed, occasionally associated with focal cell losses (Fig. 13A).

While rejection was typically a slowly progressive process, in a few cases the reaction appeared to accelerate. Pigmented territories quickly disappeared, large amounts of ectopic pigment were generated, and the eye eventually collapsed. Eyes that were processed for histology during the initial stages of this accelerated reaction showed loss of photoreceptor cells in areas overlying pigment epithelial damage (Fig. 13B). Progression beyond the point of actual photoreceptor cell loss appeared to be rapid, for in the more severely affected cases retinal damage was extensive, with a clear loss of neurons and pronounced retinal thinning.

\section{Discussion}

Our initial application of the $X$. borealis - albino $X$. laevis marking system to the problem of tracking graft-derived cells in retinal chimeras has confirmed an old (but largely untested) assumption about surgically constructed "compound eyes": If roughly half of the stage 31-35 embryonic eye is replaced by an orthotopic or heterotopic graft, then roughly half of the pigment epithelium and neural retina will derive from graft at later larval stages. For both orthotopic and heterotopic compound eyes, graft-derived neurons (including ganglion cells) populated large 

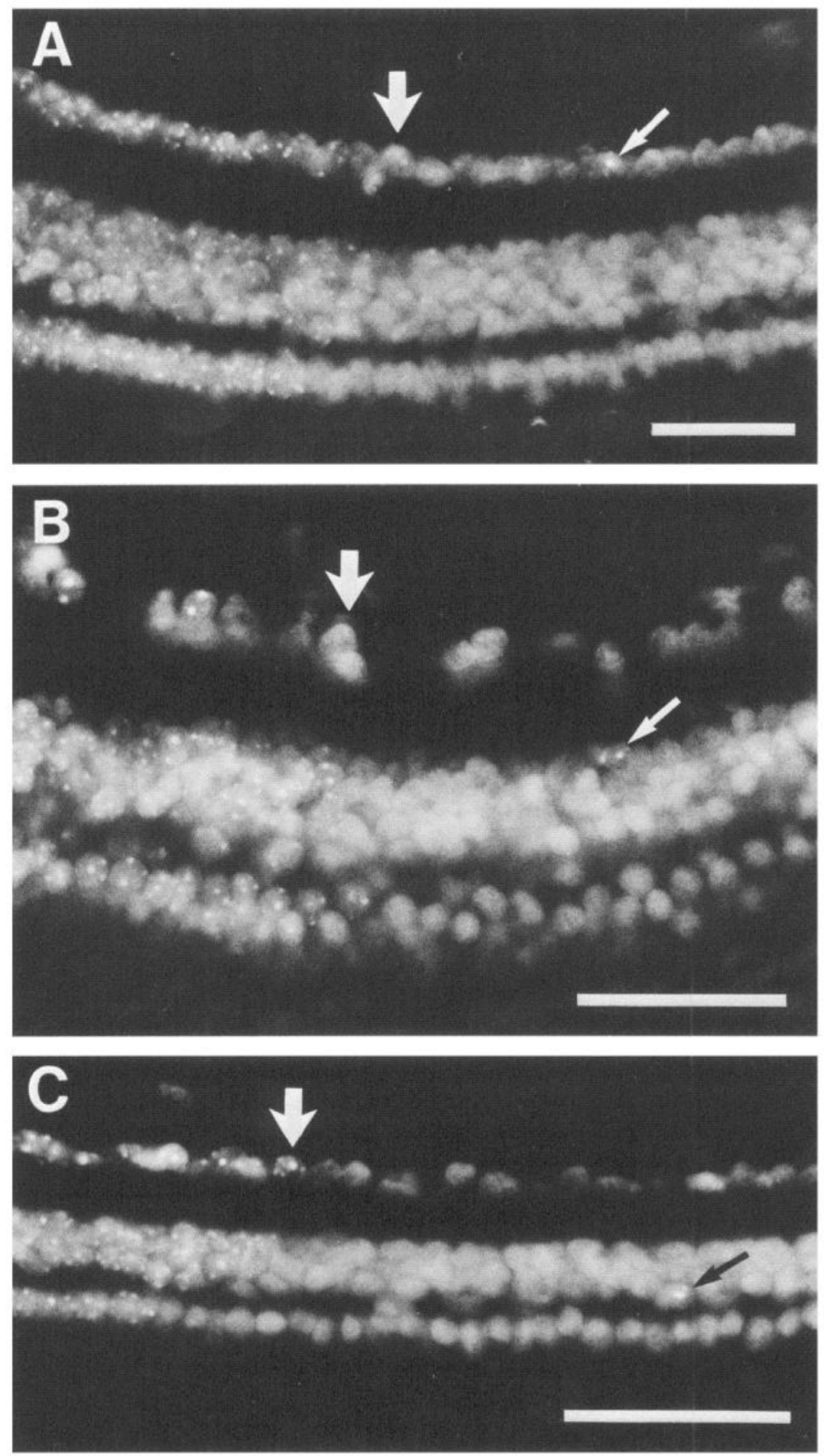

Figure 12. Displaced graft-derived cells in the retina. In each micrograph, the large vertical arrow at the vitreal surface marks the border between $X$. borealis (to the left) and $X$. laevis (to the right ) territories of neural retina. Single displaced $X$. borealis cells within $X$. laevis retinal territories are indicated by the small, slanted arrows in the ganglion cell layer $(A)$, at the inner surface of the inner nuclear layer $(B)$, and at the outer surface of the inner nuclear layer $(C)$. Scale bars, $25 \mu \mathrm{m}(A) ; 50 \mu \mathrm{m}(B, C)$. and usually coherent territories of temporal retina, with sample means ranging between 43 (for $\mathrm{TINr}$ eyes) and $51 \%$ (for $\mathrm{TrNr}$ eyes) of the total retinal surface area. These quantitative data were drawn from cases in which the graft fragment occupied at least one-third of the ocular circumference at 24-36 hr after grafting. Of equal interest, the single-cell resolution of the system also disclosed a measure of local cell mixing, laminar misalignment, and cell displacement along graft-host borders, features that may come to enlarge our understanding of retinal histogenesis.
We did not find evidence for attenuation of graft-derived territories during growth, or for invasive expansion of hostderived tissues into areas initially occupied by graft-derived tissue - one of several hypotheses considered by Gaze and Straznicky (1980). On the contrary, grafts from our relatively smalleyed $X$. borealis stocks nearly always slightly expanded their ocular territories during growth. The increased variability in graft-derived retinal territories in heterotopic compound eyes could, in principle, be caused by variations in the distribution of mitotic activity around the circumference of the eye. For 
Figure 13. Host rejection of graft-derived tissues. $A$, Photomicrograph of a section from an eye that, on the basis of its appearance in the living animal, was judged to be in the early stages of rejection. Several sites were found where large clumps of pigment $(p)$ had accumulated amidst photoreceptor outer segments, and smaller pigment granules were present in the inner retinal layers (arrows). This case was atypical in that, although rejection of the pigment epithelium had not progressed to an advanced stage, there was a focal loss of cells in the ganglion cell layer ( $G$, within area bounded by the bracket) and focal alterations in the lamination of inner and outer nuclear layers. By fluorescence microscopy all retinal cells within this field and that in $B$ were found to be $X$. borealis. $B$, Photomicrograph of a case of an eye with advanced rejection of the pigment epithelium. The pigment epithelium $(P E)$ in this eye was reduced to the thin band of pigment closely apposed to nuclei of the outer nuclear layer $(O)$, while choroidal tissues $(\mathrm{CH})$ contained unusually large amounts of pigment. Lamination of the outer nuclear layer was poor, and the remaining photoreceptors lacked outer segments. Lamination and cell number in the inner nuclear and ganglion cell layers appeared normal. Cresyl violetstained paraffin sections. Scale bars, 50 $\mu \mathrm{m}$.
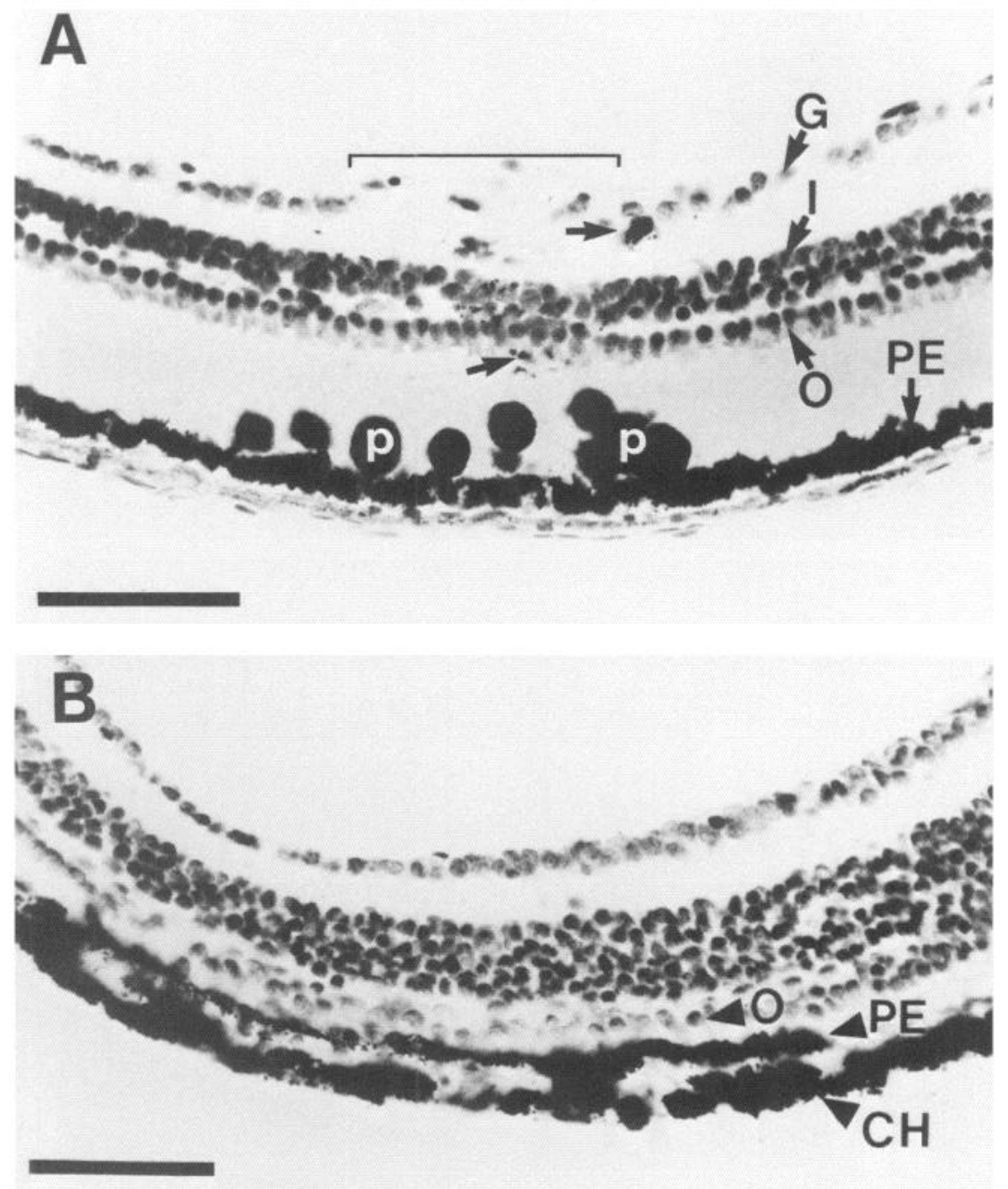

example, positional mismatches between grafted and host tissue could evoke intercalary growth of cells bordering the line of surgical apposition (French et al., 1976). However, an elegant series of half-eye transplants, using unlabeled hosts and donor tissue labeled with fluorescent dextran, failed to demonstrate the marked dilution of label in heterotopic (TINr) compound eyes that would result from differential proliferation of graftderived cells near graft-host borders (O'Rourke and Fraser, 1986).

A further possible source of variability is the ventral-to-dorsal gradient of mitotic activity that arises in the normal Xenopus retina at about stage 53, and results in more rapid growth of ventral retina thereafter (Jacobson, 1976; Beach and Jacobson, 1979). Proliferative gradients in the half-eye fragments of both $\mathrm{TrNr}$ and $\mathrm{NINr}$ compound eyes would be approximately normal, while those of $\mathrm{TINr}$ and $\mathrm{DrNr}$ eyes might be discontinuous (Straznicky and Tay, 1977; Beach and Jacobson, 1979) and contribute to the increased variability of graft-derived territories in these latter 2 classes of compound eyes.

The roughly similar territories occupied by graft-derived retinal neurons in the various classes of heterotopic compound eyes belie marked differences in the retinotectal projections of these eyes. Under a variety of experimental conditions, $\mathrm{NINr}$ compound eyes form what are conventionally referred to as "double nasal" maps, in which the original dorsoventral and nasotemporal axes of the grafted fragment are preserved and both graft and host sectors project to the entire tectal surface (Gaze et al., 1963, 1965; Hunt and Jacobson, 1974; Berman and Hunt, 1975). By contrast, when prepared under the conditions used for this study, $\mathrm{TINr}$ compound eyes form projections in which the dorsoventral axis of the graft-derived segment appears to have reversed polarity relative to the grafted fragment's original orientation (Hunt and Jacobson, 1973b; Hunt and Frank, 1975; Gaze and Straznicky, 1980). Finally, DrNr compound eyes form continuous, normally oriented retinotectal projections that appear to require a $90^{\circ}$ rotation of axes within graft-derived retinal tissues (Ide et al., 1979). Electrophysiological mapping of interspecific compound eyes identical to those prepared for this report has shown similar alterations in the polarities of graft-derived tissues (Hunt et al., 1986). Thus, differences in retinotectal projections cannot be explained by major discrepancies in the territories occupied by graft-derived cells.

Variations in the configurations of graft-host borders included laminar misregistration, local cell mixing, and the occurrence of displaced cells. Misregistration of graft-host borders in the different nuclear laminae may stem from the changes in cell density and ocular shape that attend growth of the eye. The occurrence of local cell mixing along graft-host borders within postmitotic retinal territories could result from the mixing of graft and host progenitor cells in the peripheral germinal neu- 
roepithelium, or from the mixing of postmitotic neurons as they migrate to assume their final positions. Clearly, some mixing of germinal cells does occur, generating isolated files of graft and host ncurons similar to those illustrated in Figure $9 C$, but the incidence of discrete files suggests that such large-scale transpositions are rare events. The idea that a fine-grained mixing occurs during migration is supported by the observation that more mixing occurs in the inner nuclear and ganglion cell layers, the layers furthest removed from the ventricular surface at which cells are generated, than in the outer nuclear layer, whose cells remain relatively close to their site of origin.

More radically displaced cells, those isolated by 5 or more cell diameters from other members of their genetic cohort, may include glial and endothelial cells, but their nuclear morphology suggests that many will prove to be neurons. Their "ectopic" positions could reflect a similar isolation of one or a few germinal cells within a region of the growth zone otherwise populated by the contrasting genotype. Because the laminar distribution of displaced cells was not random, one would have to propose that such isolated germinal cells generated a restricted array of laminar phenotypes, and that progenitors for photoreceptors were never so displaced. A more likely, but no less intriguing, possibility is that there is a selective movement of postmitotic neuronal perikarya within the plane of the retina whereby members of individual neuron classes come to be distributed in nonrandom and often widely spaced arrays or mosaics (Wassle and Reimann, 1978).

In summary, the $X$. borealis $-X$. laevis genetic marking system promises to substantially refine analyses of retinotectal projections formed by compound retinas. We found a rather good correlation between the template of graft and host tissues established in the germinal zone at the front of the embryonic eye during the immediate postoperative period and the eventual, largely coherent territories occupied by graft- and host-derived cells at later larval stages. Moreover, the ocular territories populated by $X$. borealis cells closely matched those reported for analogous grafts bearing (lower-resolution) intraspecific cell markers (Conway et al., 1980; Hunt et al., 1982), suggesting that chimeric patterns are not substantially perturbed by possibly dissimilar growth rates or other differences between the 2 species. The single-cell resolution of the marker made possible the recognition of numerous variations in the distribution of cells about graft-borders, which, when combined with more precise identification of neuronal phenotypes, should provide additional insights about the movements of postmitotic neurons during retinal histogenesis.

\section{References}

Beach, D. H., and M. Jacobson (1979) Patterns of cell proliferation in the developing retina of the clawed frog in relation to blood supply and position of the choroidal fissure. J. Comp. Neurol. 183:625-632.

Berman, N., and R. K. Hunt (1975) Visual projections to the optic tecta in Xenopus after partial extirpation of the embryonic eye. $\mathrm{J}$. Comp. Neurol. 162: 23-42.

Brown, D. D., and K. Sugimoto (1974) The structure and evolution of ribosomal and 5S DNAs in Xenopus laevis and Xenopus mulleri. Cold Spring Harbor Symp. Quant. Biol. 38: 501-505.

Constantine-Paton, M., E. Pitts, and T. A. Reh (1983) The relationship between retinal axon ingrowth, terminal morphology, and terminal patterning in the optic tectum of the frog. J. Comp. Neurol. 218: 297313.

Conway, K., K. Feiock, and R. K. Hunt (1980) Polyclones and patterns in growing Xenopus eye. Curr. Top. Dev. Biol. 15: 217-317.

Cowan, W. M., and R. K. Hunt (1985) The development of the ret- inotectal projection: An overview. In Molecular Bases of Neural Development, G. M. Edelman, W. E. Gall, and W. M. Cowan, eds., pp. 389-428, Wiley, New York.

Easter, S. (1985) The continuous formation of the retinotectal map in goldfish, with special attention to the role of the axonal pathway. In Molecular Bases of Neural Development, G. M. Edelman, W. E. Gall, and W. M. Cowan, eds., pp. 429-452, Wiley, New York.

Elsdale, T. R., M. Fischberg, and S. Smith (1958) A mutation that reduces nucleolar number in Xenopus laevis. Exp. Cell Res. 14:642643.

Feldman, J. D., and R. M. Gaze (1975) The development of half-eyes in Xenopus tadpoles. J. Comp. Neurol. 162: 13-22.

French, V., P. M. Bryant, and S. V. Bryant (1976) Pattern regulation in epimorphic fields. Science 193: 969-981.

Gaze, R. M., and C. Straznicky (1980) Stable programming for map orientation in disarranged embryonic eyes in Xenopus. J. Embryol. Exp. Morphol. 55: 143-165.

Gaze, R. M., M. Jacobson, and G. Szekely (1963) The retinotectal projection in Xenopus with compound eyes. J. Physiol. (Lond.) 165. 484-499.

Gaze, R. M., M. Jacobson, and G. Szekely (1965) On the formation of connections by compound eyes in Xenopus. J. Physiol. (Lond.) 176: 409-417.

Gaze, R. M., J. D. Feldman, J. Cooke, and S.-H. Chung (1979) The orientation of the visuotectal map in Xenopus: Developmental aspects. J. Embryol. Exp. Morphol. 53: 39-66.

Gurdon, J. B. (1967) African clawed frogs. In Methods in Developmental Biology, F. H. Wilt and N. K. Wessels, eds., pp. 75-84, Crowell, New York.

Harris, W. A. (1984) Axonal pathfinding in the absence of normal pathways and impulse activity. J. Neurosci. 4: 1153-1162.

Harrison, R. G. (1933) Some difficulties of the determination problem. Am. Naturalist. 67: 306-321.

Harrison, R. G. (1945) Relations of symmetry in the developing embryo. Trans. Connecticut Acad. Arts Sci. 36: 277-330.

Hollyfield, J. G. (1971) Differential growth of the neural retina in Xenopus laevis larvae. Dev. Biol. 24: 264-286.

Hoperskaya, O. A. (1975) The development of animals homozygous for a mutation causing periodic albinism (aP) in Xenopus laevis. $\mathrm{J}$. Embryol. Exp. Morphol. 34: 253-264.

Hunt, R. K., and E. Frank (1975) Neuronal locus specificity: Transrepolarization of Xenopus embryonic retina after the time of axial specification. Science 189: 563-565.

IIunt, R. K., and M. Jacobson (1972) Development and stability of positional information in Xenopus retinal ganglion cells. Proc. Natl. Acad. Sci. USA 69: 780-783.

Hunt, R. K., and M. Jacobson (1973a) Specification of positional information in retinal ganglion cells of Xenopus; assays for analysis of the unspecified state. Proc. Natl. Acad. Sci. USA 70: 507-511.

Hunt, R. K, and M. Jacobson (1973b) Neuronal locus specificity: Altered pattern of spatial deployment in fused fragments of embryonic Xenopus eyes. Science 180:509-511.

Hunt, R. K., and M. Jacobson (1974) Development of neuronal locus specificity in Xenopus retinal ganglion cells after surgical transection or after fusion of whole eyes. Dev. Biol. 40: 1-15.

Hunt, R. K., R. Tompkins, D. Reinschmidt, L. Bodenstein, and R. K. Murphy (1982) Starting points for a developmental genetics of nerve patterns. Am. Zool. 22: 185-207.

Hunt, R. K., J. Kilty, and S. O'Gorman (1986) "Regulated" visuotectal projections in young adult Xenopus raised from embryonic stages with a genetically marked "compound eye." Soc. Neurosci. Abstr. 12: 769.

Ide, C. F., B. E. Kosofsky, and R. K. Hunt (1979) Control of pattern duplication in the retinotectal system of Xenopus. Suppression of duplication by eye-fragment interactions. Dev. Biol. 69: 337-360.

Jacobson, M. (1968a) Development of neuronal specificity in retinal ganglion cells of Xenopus. Dev. Biol. 17: 202-218.

Jacobson, M. (1968b) Cessation of DNA synthesis in retinal ganglion cells correlated with the time of specification of their central connections. Dev. Biol. 17: 219-232.

Jacobson, M. (1976) Histogeneis of retina in the clawed frog with implications for the pattern of development of retinotectal connections. Dev. Biol. 103: 541-545.

Meyer, R. L. (1982) Ordering of retinotectal connections: A multivariate operational analysis. Curr. Top. Dev. Biol. 17: 101-145.

Nieuwkoop, P. D., and J. Faber (1967) A Normal Table of Xenopus 
laevis (Daudin). Elsevier/North Holland, Amsterdam.

O'Gorman, S., J. Kilty, and R. K. Hunt (1985) Retinal chimerae of Xenopus: Analysis of neural graft integration and growth using a cell autonomous genetic marker. Soc. Neurosci. Abstr. 11: 647.

O'Rourke, N. A., and S. E. Fraser (1986) Pattern regulation in the eyebud of Xenopus studied with a vital-dye fiber-tracing technique. Dev. Biol. 114: 277-288.

Pardue, M. L. (1974) Localization of repeated DNA sequences in Xenopus chromosomes. Cold Spring Harbor Symp. Quant. Biol. 38: 475-482.

Reinschmidt, D. C., S. J. Simon, E. P. Volpe, and R. Tompkins (1979) Production of tetraploid and homozygous diploid amphibians by suppression of first cleavage. J. Exp. Zool. 210:137-143.

Sperry, R. W. (1965) Embryogenesis of behavioral nerve nets. In Organogenesis, R. L. DeHaan and H. Ursprung, eds., pp. 161-186, Saunders, Philadelphia.

Stone, L. S. (1960) Polarization of the retina and development of vision. J. Exp. Zool. 154: 85-93.

Straznicky, K., and R. M. Gaze (1971) The growth of the retina in Xenopus laevis: An autoradiographic study. J. Embryol. Exp. Morphol. 26: 67-79.
Straznicky, C., and R. M. Gaze (1980) Stable programming for map orientation in fused eye fragments in Xenopus. J. Embryol. Exp. Morphol. 55: 123-142.

Straznicky, K., and D. Tay (1977) Retinal growth in double dorsal and double ventral compound eyes in Xenopus. J. Embryol. Exp. Morphol. 40: 175-185.

Szekely, G. (1966) Embryonic determination of neural connections Adv. Morphogr. 5: 181-219.

Thiebaud, C. H. (1983) A reliable new cell marker in Xenopus. Dev. Biol. 98: 245-249.

Wassle, H., and H. J. Reimann (1978) The mosaic of nerve cells in the mammalian retina. Proc. $R$. Soc. Lond. [Biol.] 200: 441-461.

Willshaw, D. J., J. W. Fawcett, and R. M. Gaze (1983) The visuotectal projections made by Xenopus "pie slice" compound eyes. J. Embryol. Exp. Morphol. 74: 29-45.

Winklbauer, R., and P. Hausen (1983) Development of the lateral line system in Xenopus laevis. I. Normal development and cell movement in the supraorbital system. J. Embryol. Exp. Morphol. 76: 265-281.

Wolpert, K. (1971) Positional information and pattern formation. Curr. Top. Dev. Biol. 6: 183-224. 